\title{
Response of Potato Genotypes to Bacterial Wilt Caused by Ralstonia Solanacearum (Smith)(Yabuuchi et al.) In the Tropical Highlands
}

\author{
Jane Muthoni • Hussein Shimelis • Rob Melis • \\ Z. M. Kinyua \\ Published online: 27 August 2013 \\ (C) The Author(s) 2013. This article is published with open access at Springerlink.com
}

\begin{abstract}
Potato varietal resistance to bacterial wilt disease caused by Ralstonia solanacearum Yabuuchi et al., (Microbiology and Immunology 39:897-904, 1995) is the best management of the disease. Because the causal pathogen exhibits strong host-pathogen-environment interaction, screening the potential parents for resistance under the target growing environmental conditions is the first important step for effective resistance breeding. The objective of this study was to determine the response to bacterial wilt of selected potato genotypes currently grown by farmers in Kenya and candidate clones from the International Potato Center to identify parents that can be used in the local breeding program to develop resistant cultivars. A study was carried out at Kabete, Kenya for three consecutive seasons between November 2011 and February 2013. Thirty six potato genotypes were planted on an inoculated field at the Kenya Agricultural Research Institute (KARI), Kabete using alpha lattice experimental design with three replications. Data collected were days from planting to onset of wilting (DTOW), bacterial wilt incidence (BWI), total tuber weight (ton $\mathrm{ha}^{-1}$ ) (TTW), total tuber numbers/hectare (TTN), proportion of ware sized tubers (PWTTW), proportion of symptomatic tubers based on weight (PSTTW), proportion of symptomatic tubers based
\end{abstract}

J. Muthoni $\cdot$ H. Shimelis $\cdot$ R. Melis

African Centre for Crop Improvement, College of Agriculture, Engineering and Science, School of Agricultural, Earth and Environmental Sciences, University of KwaZulu-Natal, Private Bag X01, Scottsxille 3209, Pietermaritzburg, South Africa

J. Muthoni $(\bowtie)$

National Potato Research Centre, Kenya Agricultural Research Institute (KARI), Tigoni, Kenya

e-mail: jayney480@yahoo.com

\section{Z. M. Kinyua}

National Agricultural Research Laboratories, Kenya Agricultural Research Institute (KARI), Nairobi, Kenya on tuber numbers (PSTTN) and latent infection (LI) of the tubers. Almost, all the potato genotypes evaluated in this study were susceptible to bacerial wilt. Ranking of genotypes based on resistance differed among the three seasons. On average, the three most resistant genotypes were Kenya Karibu, Kenya Sifa and Ingabire. The study identified eight potato genotypes (Meru, Ingabire, Kenya Karibu, Sherekea, Kihoro, Tigoni, Bishop Gitonga and Cangi) to be used as promising parents for subsequent crosses. The chosen genotypes are prolific in pollen production and popularly grown by Kenyan farmers.

Resumen La Resistencia varietal de la papa a la enfermedad de la marchitez bacteriana, causada por Ralstonia solanacearum Yabuuchi et al., (Microbiology and Immunology 39:897-904, 1995), es el mejor manejo de la enfermedad. Considerando que el agente patógeno causal presenta una interacción fuerte hospedante-patógeno-ambiente, las pruebas de padres potenciales para resistencia bajo condiciones ambientales de crecimiento enfocadas, es el primer paso importante para el mejoramiento efectivo para la resistencia. El objetivo de este estudio fue determinar la respuesta a la marchitez bacteriana de genotipos de papa selectos que actualmente se cultivan por productores en Kenia y clones candidatos del Centro Internacional de la Papa, para identificar padres que pudieran usarse en el programa local de mejoramiento para desarrollar variedades resistentes. Un estudio se efectuó en Kabete, Kenia, durante tres ciclos consecutivos entre noviembre de 2011 y febrero de 2013. Se plantaron 36 genotipos de papa en un campo inoculado en el Instituto de Investigaciones Agrícolas de Kenia (KARI). En Kabete se usó un diseño de látice alfa con tres repeticiones. Los datos tomados fueron los días desde la siembra hasta el establecimiento del marchitamiento (DTOW), incidencia de la marchitez bacteriana (BWI), peso total de tubérculo (ton $\mathrm{ha}^{-1}$ ) (TTW), número total de tubérculos/ha (TTN), proporción de tubérculos de tamaño comercial (PWTTW), proporción de tubérculos sintomáticos con base en 
Table 1 List and sources of potato genotypes used in the study

\begin{tabular}{|c|c|c|}
\hline Genotype & Source/pedigree & Year of release \\
\hline Desiree & The Netherlands & 1972 \\
\hline Tigoni & CIP & 1998 \\
\hline Kenya Sifa & CIP & 2002 \\
\hline Kihoro & Farmers' variety & - \\
\hline Meru & Farmers' variety & - \\
\hline Nyayo & Farmers' variety & - \\
\hline Ingabire & CIP & 1998 \\
\hline Roslin Tana & Scotland & 1974 \\
\hline Kenya Baraka & Scotland & 1973 \\
\hline Kenya Furaha ${ }^{1}$ & CIP & 1998 \\
\hline 393385.57 & CIP & Not yet released \\
\hline Tigoni Long $^{1}$ & Farmers' variety & - \\
\hline Arka & The Netherlands & - \\
\hline Kerr's Pink & Scotland & 1927 \\
\hline Dutch Robyjn & The Netherlands & 1945 \\
\hline Roslin Bvumbwe & Scotland & 1974 \\
\hline Sterling & & - \\
\hline Bishop Gitonga & Farmers' variety & - \\
\hline Annete & Germany & 1972 \\
\hline Purple Gold & CIP & 2010 \\
\hline Pimpernel & The Netherlands & - \\
\hline Kenya Mpya & CIP & 2010 \\
\hline B53 & Scotland & 1953 \\
\hline Sherekea & CIP & 2010 \\
\hline Ngure $^{1}$ & Farmers' variety & - \\
\hline Asante & CIP & 1998 \\
\hline Kenya Mavuno & CIP & 2002 \\
\hline Saturna $^{1}$ & Germany & - \\
\hline 396286.6 & CIP & Not yet released \\
\hline 394906.6 & CIP & Not yet released \\
\hline 387164.4 & CIP & Not yet released \\
\hline 394903.3 & CIP & Not yet released \\
\hline 394034.7 & CIP & Not yet released \\
\hline 394905.8 & CIP & Not yet released \\
\hline 394895.7 & CIP & Not yet released \\
\hline 394904.17 & CIP & Not yet released \\
\hline Cangi $^{2}$ & Farmers' variety & - \\
\hline Romano $^{2}$ & The Netherlands & - \\
\hline Kenya Karibu $^{2}$ & CIP & 2002 \\
\hline $393382.44^{2}$ & CIP & Not yet released \\
\hline
\end{tabular}

${ }^{2}=$ Not included in the first season. ${ }^{\mathrm{I}}=$ Not included in the second and third seasons. - Not available

el peso (PSTTW), proporción de tubérculos sintomáticos con base en el número de tubérculos (PSTTN) e infección latente (LI) de los tubérculos. Casi todos los genotipos de papa evaluados en este estudio fueron susceptibles al marchitamiento bacteriano. La clasificación de los genotipos con base en la resistencia varió entre los tres ciclos de cultivo. En promedio, Los tres genotipos más resistentes fueron Kenya Karibu, Kenya Sifa, e Ingabire. El estudio identificó ocho genotipos de papa ((Meru, Ingabire, Kenya Karibu, Sherekea, Kihoro, Tigoni, Bishop Gitonga y Cangi) para usarse como progenitores prometedores para cruzas subsecuentes. Los genotipos seleccionados son prolíficos en producción de polen y se cultivan popularmente por los productores kenianos.

Keywords Bacterial wilt · Potato $\cdot$ Resistance breeding

\section{Introduction}

Potato (Solanum tuberousm L.) production in Kenya has not achieved its potential due to several constraints including low soil fertility, inadequate supply of certified seed potatoes, use of unimproved low yielding varieties, and diseases. The most common diseases in the country include late blight, viral infections and bacterial wilt (Kaguongo et al. 2008). Bacterial wilt, caused by Ralstonia solanacearum (Yabuuchi et al. 1995),is the second most important potato disease after late blight locally and globally (Kaguongo et al. 2008). The disease has been estimated to affect about 1.7 million hectares in approximately 80 countries worldwide, with global damage estimates of over USD 950 million per annum (Champoiseau et al. 2009). Bacterial wilt has been reported to cause yield losses of between 50 and $100 \%$ in Kenya (Otipa et al. 2003), while in Uganda, losses of up to $30 \%$ (Alacho and Akimanzi 1993), with occasional losses of up to $100 \%$, have been reported (Kakuhenzire et al. 1993). This disease has no effective means of control because crop protection chemicals and biological controls are ineffective and expensive (Smith et al. 1998; Champoiseau et al. 2010). In addition, phytosanitary methods such as quarantine are either expensive or difficult to apply (Martin and French 1985; Muthoni et al. 2010), and cultural methods such as crop rotations are largely impractical because the farms are too small to allow effective rotation. Furthermore, the pathogen has a wide host range and it persists for a long time in the soil (Kaguongo et al. 2008; Muthoni et al. 2010).

Development of resistant cultivars is currently the best option for managing bacterial wilt, however, there are no known potato cultivars with resistance. Cultivars such as Cruza 148 and Molinera have been found to have some degree of tolerance to bacterial wilt but still transmit latent infection to their progeny tubers (French 1994). In addition, the resistance has been shown to be very unstable due to its strong host-pathogen-environment interaction (French and Lindo 1982; Tung et al. 1990, 1992a; Tung 1992). Therefore, a pathogen race at one location may overcome the resistance effective at another location (Grimsley and Hanson 1998); more than one race may occur in a given field (Martin and French 1985). Due to this, an essential step in the 
Table 2 Rainfall and temperatures in the experimental site during the experimental period

\begin{tabular}{|c|c|c|c|c|c|c|c|c|c|c|c|c|c|c|c|c|c|}
\hline \multirow[b]{2}{*}{ Month } & \multicolumn{3}{|l|}{2011} & \multicolumn{12}{|l|}{2012} & \multicolumn{2}{|l|}{2013} \\
\hline & Oct. & Nov. & Dec. & Jan. & Feb. & March & April & May & June & July & Aug. & Sept. & Oct. & Nov. & Dec. & Jan. & Feb. \\
\hline Total rainfall (MM) & 154.4 & 351 & 96.2 & 9.4 & 75.6 & 49.1 & 686.6 & 3746.6 & 456 & 26 & 96.8 & 33.5 & 416.1 & 252.1 & 289.4 & 89.2 & 6 \\
\hline Number of rainy days & 16 & 12 & 4 & 1 & 3 & 3 & 21 & 23 & 11 & 3 & 2 & 2 & 12 & 15 & 12 & 7 & 2 \\
\hline Mean temp. & 16.8 & 17.8 & 18.4 & 19.4 & 16.9 & 19.7 & 18.0 & 16.2 & 14.9 & 14.8 & 16.24 & 23.1 & 24.6 & 23 & 22 & 23.1 & 25.2 \\
\hline
\end{tabular}

Table 3 Analysis of variance on colony forming units (cfu) per gram of soil sampled during the three seasons at KARI Kabete

\begin{tabular}{llll}
\hline Source of variation & DF & MS & Fpr. \\
\hline Block & 2 & 2249000000000.00 & \\
Season & 2 & 24570000000000.00 & $<.001^{*}$ \\
Sampling time & 2 & 281100000000000.00 & $<.001^{*}$ \\
Season * Sampling time & 4 & 10470000000000.00 & $<.001^{*}$ \\
Residual & 205 & 801700000000.00 & \\
Total & 215 & &
\end{tabular}

*=significant at $P \leq 0.05$

development of resistant varieties is screening of the germplasm at the target production environment to identify promising clones for breeding (Martin and French 1985).

Breeding programs to develop resistant cultivars were initiated in many parts of the world, but acceptable cultivars with good tolerance to bacterial wilt are yet to be identified in Kenya (Ateka et al. 2001). Resistant potato clones have recently been identified by International Potato Centre (CIP) scientists. This resistance needs to be incorporated into the popular but susceptible Kenyan potato cultivars so as to increase potato production in Kenya. Screening the clones

Table 4 Mean colony forming units (cfu) per gram of soil sampled during the three seasons at KARI Kabete

\begin{tabular}{lllll}
\hline Sampling time & Season 1 & Season 2 & Season 3 & Mean \\
\hline Before planting & $855000 \mathrm{a}$ & $832500 \mathrm{a}$ & $1936250 \mathrm{a}$ & $1207917 \mathrm{a}$ \\
60 days after planting & $3352500 \mathrm{c}$ & $5361250 \mathrm{c}$ & $5556667 \mathrm{~b}$ & $4756806 \mathrm{c}$ \\
After harvesting & $1373750 \mathrm{~b}$ & $1490000 \mathrm{~b}$ & $1568333 \mathrm{a}$ & $1477361 \mathrm{a}$ \\
Mean & $1860417 \mathrm{a}$ & $2561250 \mathrm{~b}$ & $3020417 \mathrm{c}$ & 2480694 \\
LSD $(0.05)$ for Seasons = & & & & \\
294213.1 & & & & \\
LSD $(0.05)$ for Sampling & & & & \\
$\quad$ time=294213.1 & & & & \\
LSD $(0.05)$ for Seasons * & & & & \\
Sampling time & & & & \\
$\quad=509592.0$ & & & &
\end{tabular}

Within each column, values followed by the same letter are not significantly different at $P \leq 0.05$ for resistance under local environmental conditions is the first important step for effective resistance breeding. This study was carried out to determine the reaction to bacterial wilt of the potato genotypes currently grown by farmers in Kenya as well as other clones from CIP so as to identify parents that can be used in the local breeding program to develop resistant cultivars.

\section{Materials and Methods}

Study Site

The experiment was carried out at National Research Laboratories (NARL), Kabete Station of the Kenya Agricultural Research Institute (KARI). The KARI-Kabete station is located $7 \mathrm{~km} \mathrm{~N}$.W. of Nairobi at an altitude of $1795 \mathrm{~m}$ above sea level, latitude of $1^{\circ} 15^{\prime} 31.64$ " S and longitude $36^{\circ} 46^{\prime} 17.96^{\prime \prime} \mathrm{E}$ (Jaetzold et al. 2006a). The average

Table 5 Analysis of variance: Days to onset of wilting and final BWI of 36 potato genotypes planted at KARI Kabete for three consecutive seasons

\begin{tabular}{|c|c|c|c|c|c|}
\hline \multirow[t]{2}{*}{ Source of variation } & \multirow[t]{2}{*}{ DF } & \multicolumn{2}{|l|}{ DTOW } & \multicolumn{2}{|c|}{ FINAL BWI } \\
\hline & & MS & Fpr. & MS & Fpr. \\
\hline \multicolumn{6}{|l|}{ Season I } \\
\hline Block & 2 & 295.85 & & 166.07 & \\
\hline Genotype & 35 & 142.57 & $0.011 *$ & 305.79 & $<.001 *$ \\
\hline Residual & 70 & 74.93 & & 75.71 & \\
\hline \multicolumn{6}{|l|}{ Season II } \\
\hline Block & 2 & 41.61 & & 457.2 & \\
\hline Genotype & 35 & 48.22 & 0.738 & 207.2 & $0.007^{*}$ \\
\hline Residual & 70 & 58.84 & & 104.1 & \\
\hline \multicolumn{6}{|l|}{ Season III } \\
\hline Block & 2 & 123.15 & & 0.2 & \\
\hline Genotype & 35 & 248.78 & $<.001$ & 989.1 & 0.057 \\
\hline Residual & 70 & 66.96 & & 634.0 & \\
\hline
\end{tabular}

DTOW days to onset of wilting, FINAL BWI bacterial wilt incidence at 120 days after planting

* = significant at $P \leq 0.05$ 
Fig. 1 Percent of the wilted plants 30 to 120 days after plating during the first season at KARI Kabete

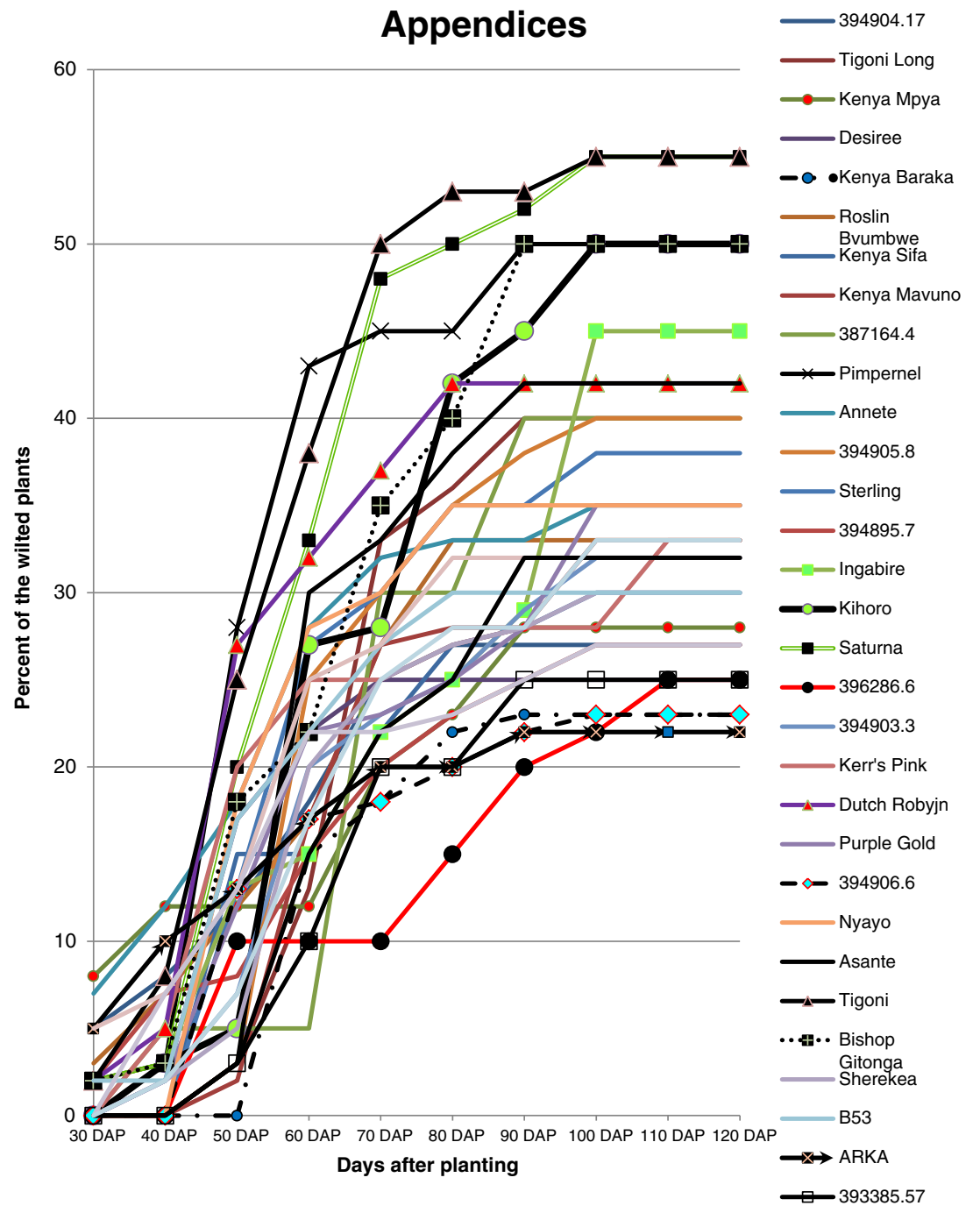

annual rainfall is $1295 \mathrm{~mm}$ with a bimodal distribution. A long rain season occurs between March and May while a short rain season is between October and December (Jaetzold et al. 2006a). The mean air temperature ranges from 13.3 to $22.9{ }^{\circ} \mathrm{C}$. The soil type is humic nitosol (alfisol) derived from quartz trachyte (UNESCO 1977) and is locally referred to as the Kikuyu Red Clay. The experiment was carried out for three consecutive seasons; 11 November 2011 to 24 February 2012 (first season), 7 April 2012 to 15 August 2012 (second season), and 16 October 2012 to 8 February 2013 (third season).

Field Layout, Inoculation and Crop Management

Thirty six bacterial wilt free potato genotypes were sourced from KARI Tigoni. The list and sources of the potato genotypes used in the study are described in Table 1 . The same genotypes were used in the second and third seasons; in the first season, four genotypes were different. Genotypes were planted at KARI, Kabete Station for screening for bacterial wilt resistance. The same field was used for three consecutive seasons; randomization was different for each season. The experimental design was an alpha lattice with four blocks each having nine plots with three replications. Each genotype was planted in four rows, and spacing was $75 \mathrm{~cm}$ (inter-row) and $30 \mathrm{~cm}$ (intra-row) giving a total of 20 plants. Di-ammonium phosphate (18:46:0) fertilizer was applied at the rate of $500 \mathrm{~kg} \mathrm{ha}^{-1}$ in furrows and thoroughly mixed with soil before planting.

To ensure uniform inoculum distribution, a susceptible tomato cultivar, Moneymaker, was transplanted in the field at a spacing of $30 \mathrm{~cm} \times 60 \mathrm{~cm}$. Two weeks after transplanting, the tomato plants were inoculated by spraying a bacterial suspension $\left(3.0 \times 10^{9} \mathrm{cfu} / \mathrm{ml}\right)$ at the base of each stem. About 6 weeks after inoculation, when at least $80 \%$ of the plants had wilted, the tomato plants were ploughed under. Thereafter, the first-season potato evaluation trial was established on the same field. In the second and third seasons, a bacterial suspension concentrated at $3.0 \times 10^{9} \mathrm{cfu} / \mathrm{ml}$ was 
Fig. 2 Percent of the wilted plants 30 to 120 days after plating during the second season at KARI Kabete

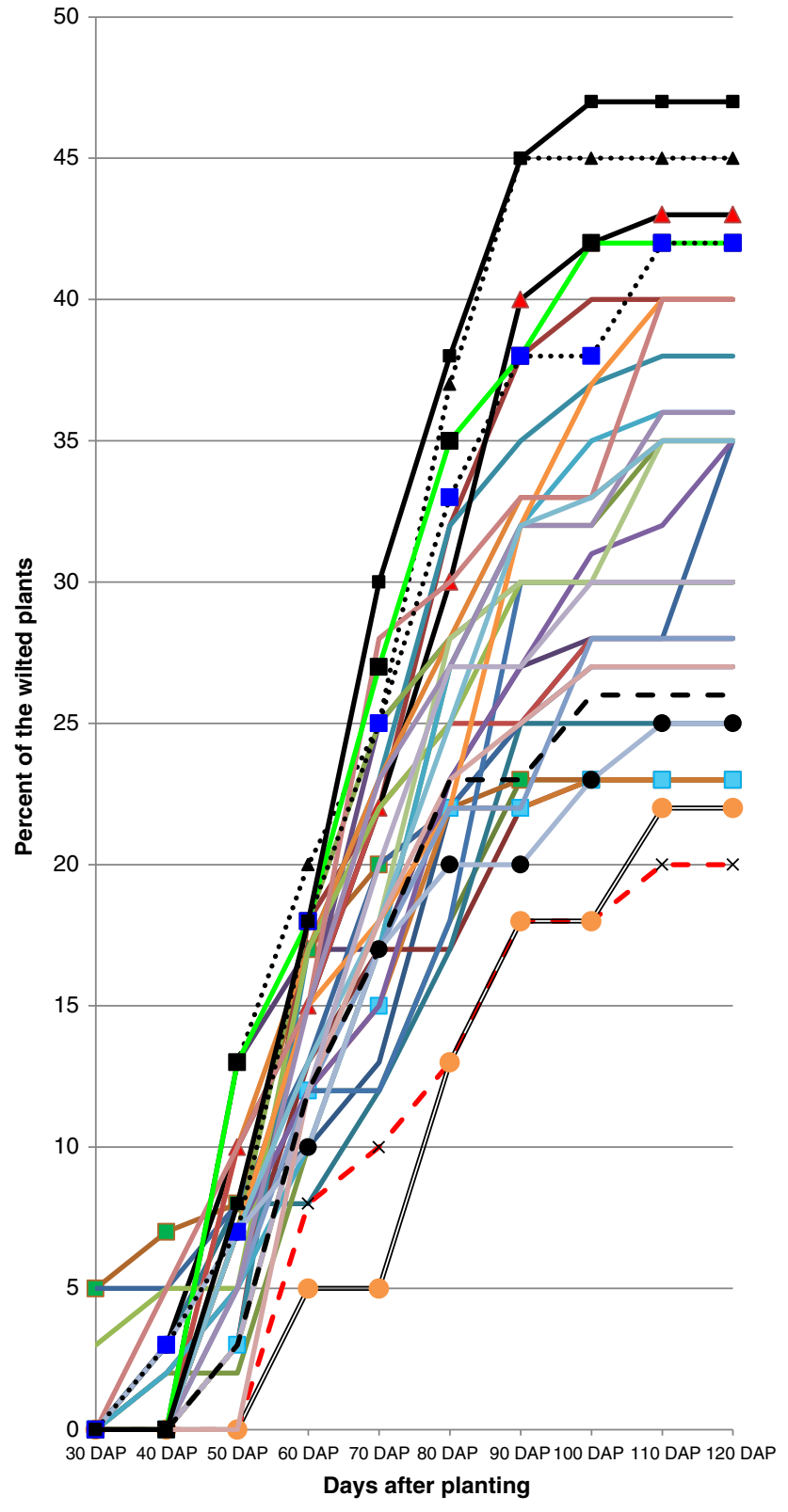

poured into the planting furrows (during planting potato tubers but before covering them) at a rate of $400 \mathrm{ml}$ per plot to boost the inoculum concentration in the soil. Weeding and other cultural management practices were carried out according to recommendations for potato production in Kenya(Kabira et al. 2006). To ensure disease progression, supplemental irrigation was provided during the dry times. In addition, workers' shoes as well as working tools were disinfested by dipping in a footbath containing $1 \%$ sodium hypochlorite when entering and leaving the field.

The minimum and maximum air temperatures were taken daily at 12.00 p.m. throughout the experimental period. This was done using a thermometer hung in a Stevenson screen near the experimental plots. The daily values were averaged on a monthly basis to give the mean monthly temperature. Daily total rainfall was captured using a rain gauge in the KARI-Kabete centre while the number of rainy days per month were recorded at the same site.

\section{Data Collection}

The potato plants were first observed for wilt symptoms 30 days after planting and then after every 10 days. At each evaluation date, all the wilting plants on each plot were counted. This was then expressed as a percentage of all the plants in the plot to give wilt incidence (BWI). Final BWI was 
Fig. 3 Percent of the wilted plants 30 to 120 days after plating during the third season at KARI Kabete

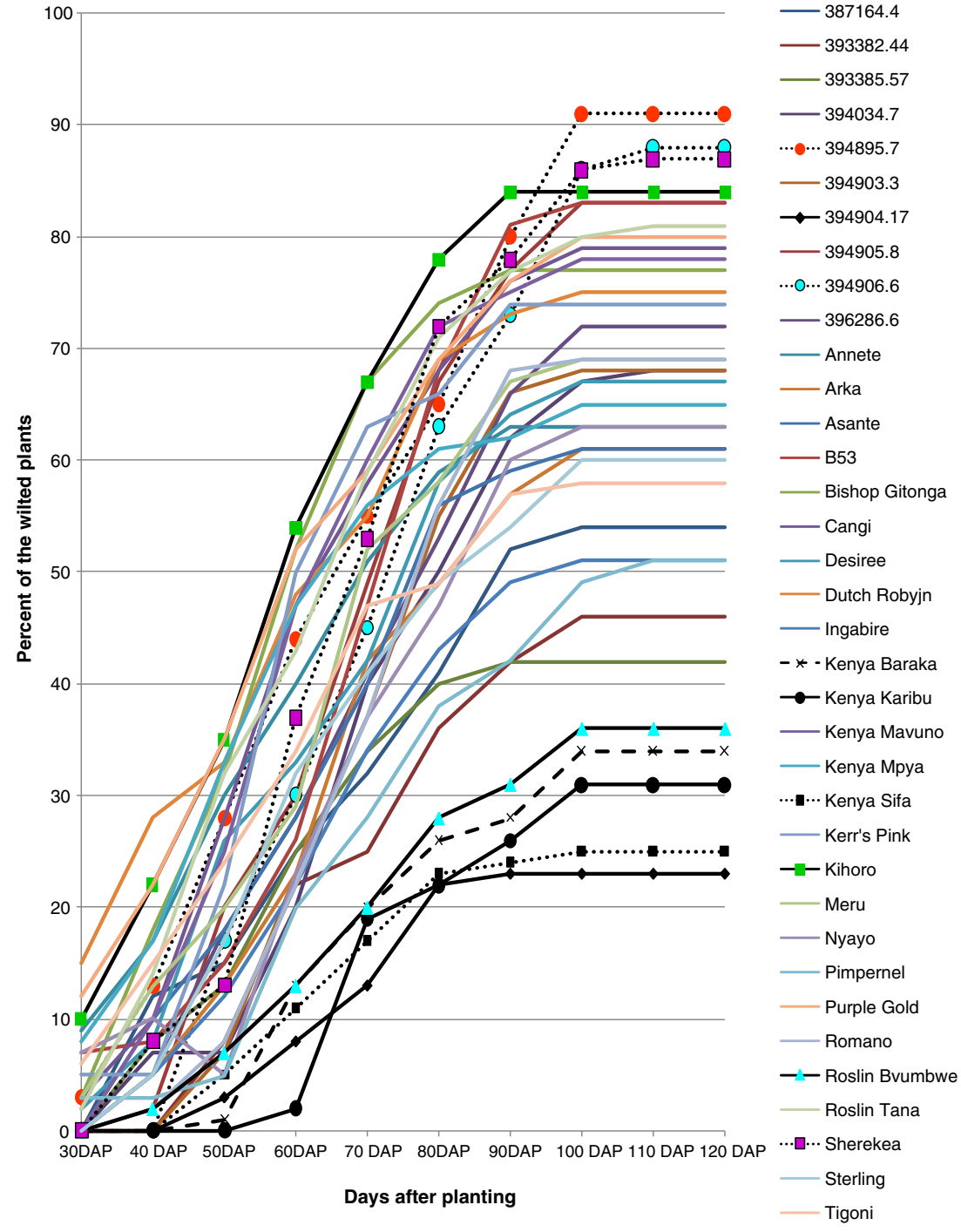

taken at 120 days after planting. Other data collected were days from planting to onset of wilting (DTOW). In each season, populations of $R$. solanacearum in the soil were determined using a modified SMSA method (Englebrecht 1994) before inoculating the field, at 60 days after planting, and after harvesting the crop. At each sampling time, 8 soil samples were evenly collected from each replicate. From each soil sample, $10 \mathrm{~g}$ were placed into a sterile conical flask and $30 \mathrm{ml}$ of sterile distilled water added. This was mixed thoroughly for $30 \mathrm{~min}$ and then allowed to stand for $5 \mathrm{~min}$. Thereafter, $1 \mathrm{ml}$ was drawn from the supernatant solution using a micro-pipette and put in a sterile Eppendorf tube. This formed the stock solution $\left(10^{\circ} \mathrm{cfu} / \mathrm{ml}\right)$. From the stock solution, $0.1 \mathrm{ml}$ was drawn and put in sterile Eppendorf tube which already contained $0.9 \mathrm{ml}$ of sterile distilled water. This formed the first dilution of the stock solution $\left(10^{-1}\right)$. This serial dilution was continued up to $10^{-3}$. From $10^{-3}$ dilution, $0.1 \mathrm{ml}$ of the suspension was drawn and plated on semi- selective media for R.solanacearum. The plates were incubated at $30^{\circ} \mathrm{C}$ for $48 \mathrm{~h}$ after which the bacterial colonies were counted. The experiment was duplicated and the mean number of bacterial colonies was reported.

Harvesting of potato tubers was done when the latest maturing genotype had reached $75 \%$ senescence. During harvest, the 6 middle plants per plot were harvested, each plant separately. The total number of tubers was counted from each of the six plants. In addition, the number of symptomatic tubers (i.e. showing rotting or bacterial ooze in the tuber eyes or soil adhering to the eyes of the tubers) and healthy looking tubers (asymptomatic) were determined. The healthy looking tubers were then categorized based on size i.e. ware $(>45 \mathrm{~mm}$ diameter) and, seed and chatts $(45>\mathrm{mm}$ diameter). Their number and weights were recorded. The weights of symptomatic and ware tubers were expressed as percentage of the total yields. The percent of symptomatic tubers were expressed as a weight, a value which is useful to determine yield loses (tons ha ${ }^{-1}$ ), and as 
Table 6 Latent infection of tubers among potato genotypes tested for three consecutive seasons at KARI Kabete

\begin{tabular}{|c|c|c|c|c|c|c|c|c|}
\hline \multicolumn{3}{|l|}{ Season I } & \multicolumn{3}{|l|}{ Season II } & \multicolumn{3}{|l|}{ Season III } \\
\hline Genotype & $\%$ LI & Rank & Genotype & $\% \mathrm{LI}$ & Rank & Genotype & $\%$ LI & Rank \\
\hline 394904.17 & 40.00 & 8.0 & 394904.17 & 40.00 & 26.5 & 394904.17 & 25.00 & 8.5 \\
\hline Tigoni Long & 33.33 & 3.5 & Kenya Mpya & 33.33 & 20.0 & Kenya Mpya & 33.33 & 17.0 \\
\hline Kenya Mpya & 46.67 & 13.0 & Desiree & 30.00 & 16.0 & Desiree & 26.00 & 11.5 \\
\hline Desiree & 40.00 & 8.0 & Kenya Baraka & 60.00 & 35.5 & Kenya Baraka & 6.67 & 2.0 \\
\hline Kenya Baraka & 50.00 & 15.5 & Roslin Bvumbwe & 46.67 & 31.5 & Roslin Bvumbwe & 50.33 & 29.0 \\
\hline Roslin Bvumbwe & 40.00 & 8.0 & Asante & 16.00 & 6.0 & Asante & 26.00 & 11.5 \\
\hline Kenya Sifa & 33.33 & 3.5 & Kenya Mavuno & 20.00 & 10.0 & Kenya Mavuno & 23.33 & 6.0 \\
\hline Kenya Mavuno & 53.33 & 20.5 & 387164.4 & 40.00 & 26.5 & 387164.4 & 20.33 & 5.0 \\
\hline 387164.4 & 60.00 & 28.5 & Annete & 20.00 & 10.0 & Annete & 45.00 & 24.5 \\
\hline Annete & 53.33 & 20.5 & 394905.8 & 50.00 & 34.0 & 394905.8 & 25.00 & 8.5 \\
\hline 394905.8 & 60.00 & 28.5 & Sterling & 20.00 & 10.0 & Sterling & 33.00 & 16.0 \\
\hline Sterling & 53.33 & 20.5 & 394895.7 & 33.33 & 20.0 & 394895.7 & 26.67 & 14.0 \\
\hline 394895.7 & 66.67 & 34.5 & Ingabire & 20.00 & 10.0 & Ingabire & 13.67 & 3.0 \\
\hline Ingabire & 60.00 & 28.5 & Kihoro & 20.00 & 10.0 & Kihoro & 50.00 & 28.0 \\
\hline Kihoro & 40.00 & 8.0 & 396286.6 & 40.00 & 26.5 & 396286.6 & 26.33 & 13.0 \\
\hline Saturna & 60.00 & 28.5 & 394903.3 & 26.67 & 14.5 & 394903.3 & 30.00 & 15.0 \\
\hline 396286.6 & 40.00 & 8.0 & Kerr's Pink & 40.00 & 26.5 & Kerr's Pink & 60.00 & 33.0 \\
\hline 394903.3 & 60.00 & 28.5 & Dutch Robyjn & 0.00 & 1.5 & Dutch Robyjn & 60.53 & 34.0 \\
\hline Kerr's Pink & 53.33 & 20.5 & Purple Gold & 33.33 & 20.0 & Purple Gold & 53.33 & 31.0 \\
\hline Dutch Robyjn & 40.00 & 8.0 & 394906.6 & 46.67 & 31.5 & 394906.6 & 35.00 & 18.5 \\
\hline Purple Gold & 53.33 & 20.5 & Nyayo & 33.33 & 20.0 & Nyayo & 53.33 & 31.0 \\
\hline 394906.6 & 53.33 & 20.5 & Kenya Sifa & 40.00 & 26.5 & Kenya Sifa & 15.00 & 4.0 \\
\hline Nyayo & 53.33 & 20.5 & Bishop Gitonga & 6.67 & 3.5 & Bishop Gitonga & 66.67 & 35.0 \\
\hline Asante & 46.67 & 13.0 & Sherekea & 33.33 & 20.0 & Sherekea & 40.00 & 20.5 \\
\hline Tigoni & 20.00 & 2.0 & B53 & 33.33 & 20.0 & B53 & 46.67 & 27.0 \\
\hline Bishop Gitonga & 40.00 & 8.0 & Arka & 20.00 & 10.0 & Arka & 25.00 & 8.5 \\
\hline Sherekea & 60.00 & 28.5 & 393385.57 & 60.00 & 35.5 & 393385.57 & 40.00 & 20.5 \\
\hline B53 & 46.67 & 13.0 & Meru & 6.67 & 3.5 & Meru & 76.67 & 36.0 \\
\hline Arka & 60.00 & 28.5 & Roslin Tana & 46.67 & 31.5 & Roslin Tana & 53.33 & 31.0 \\
\hline 393385.57 & 60.00 & 28.5 & Pimpernel & 40.00 & 26.5 & Pimpernel & 45.00 & 24.5 \\
\hline Ngure & 66.67 & 34.5 & Kenya Karibu & 0.00 & 1.5 & Kenya Karibu & 5.00 & 1.0 \\
\hline Meru & 66.67 & 34.5 & 394034.7 & 26.67 & 14.5 & 394034.7 & 25.00 & 8.5 \\
\hline Roslin Tana & 53.33 & 20.5 & Cangi & 13.33 & 5.0 & Cangi & 43.33 & 22.0 \\
\hline Kenya Furaha & 66.67 & 34.5 & Romano & 33.33 & 20.0 & Romano & 35.00 & 18.5 \\
\hline Pimpernel & 50.00 & 15.5 & Tigoni & 20.00 & 10.0 & Tigoni & 45.00 & 24.5 \\
\hline 394034.7 & 0.00 & 1.0 & 393382.44 & 46.67 & 31.5 & 393382.44 & 45.00 & 24.5 \\
\hline Mean & 49.44 & & & 30.44 & & & 36.93 & \\
\hline
\end{tabular}

$\% \mathrm{LI}=\%$ Latent infection

a number of infected tubers, a value which is used for the calculation of infection tuber rates.

Only healthy-looking tubers selected above were analyzed for latent infection by $R$. solanacearum. For each genotype across all the replications, 30 healthy-looking tubers were placed in khaki paper and delivered to the laboratory for latent infection analysis. In the laboratory, the tubers were washed and disinfested. They were then divided into five groups of six tubers each. In each group, each potato tuber had a thin slice of the tuber removed and discarded from around the stolon end using a flame-sterilized scalpel. Then strips of tuber flesh were removed with a flame-sterilized cuticle remover along the vascular ring ( $=3 \mathrm{~mm}$ wide and $3 \mathrm{~mm}$ deep); strips from the six tubers were put in a plastic bag to constitute a composite 
Table 7 Analysis of variance for some tuber yield traits of 36 potato genotypes planted at KARI Kabete for three consecutive seasons

\begin{tabular}{|c|c|c|c|c|c|c|c|c|c|c|c|}
\hline \multirow[t]{2}{*}{ Source of variation } & \multirow[t]{2}{*}{$\mathrm{DF}$} & \multicolumn{2}{|l|}{ TTN } & \multicolumn{2}{|l|}{ PSTTN } & \multicolumn{2}{|l|}{ TTW } & \multicolumn{2}{|l|}{ PSTTW } & \multicolumn{2}{|c|}{ PWTTW } \\
\hline & & MS & Fpr. & MS & Fpr. & MS & Fpr. & MS & Fpr. & MS & Fpr. \\
\hline \multicolumn{12}{|l|}{ Season I } \\
\hline Block & 2 & $2.633 \mathrm{E}+10$ & \multirow[t]{3}{*}{$<0.001 *$} & 103.6 & \multirow[t]{3}{*}{0.379} & 953.15 & \multirow[t]{3}{*}{$0.014 *$} & 65.1 & \multirow[t]{3}{*}{$0.046^{*}$} & 165.8 & \multirow[t]{3}{*}{0.244} \\
\hline Genotype & 35 & $7.526 \mathrm{E}+09$ & & 116.7 & & 80.95 & & 225.1 & & 123.6 & \\
\hline Residual & 70 & $2.348 \mathrm{E}+09$ & & 107.7 & & 43.41 & & 140.1 & & 102.0 & \\
\hline \multicolumn{12}{|l|}{ Season II } \\
\hline Block & 2 & $2.759 \mathrm{E}+09$ & \multirow[t]{3}{*}{0.616} & 15673.4 & \multirow[t]{3}{*}{0.131} & 479.6 & \multirow[t]{3}{*}{0.561} & 12010.7 & \multirow[t]{3}{*}{0.191} & 5668.0 & \multirow[t]{3}{*}{0.210} \\
\hline Genotype & 35 & $8.704 \mathrm{E}+09$ & & 247.0 & & 163.8 & & 279.9 & & 266.2 & \\
\hline Residual & 70 & $9.589 \mathrm{E}+09$ & & 180.0 & & 173.1 & & 212.6 & & 212.6 & \\
\hline \multicolumn{12}{|l|}{ Season III } \\
\hline Block & 2 & $4.401 \mathrm{E}+09$ & \multirow[t]{3}{*}{0.108} & 4564.0 & \multirow[t]{3}{*}{$<.001 *$} & 487.4 & \multirow[t]{3}{*}{$0.017 *$} & 3693.6 & \multirow[t]{3}{*}{$<0.001 *$} & 3227.5 & \multirow[t]{3}{*}{$0.035^{*}$} \\
\hline Genotype & 35 & $9.076 \mathrm{E}+09$ & & 656.3 & & 182.2 & & 572.4 & & 348.8 & \\
\hline Residual & 70 & $6.407 \mathrm{E}+09$ & & 151.1 & & 100.5 & & 187.8 & & 208.8 & \\
\hline
\end{tabular}

$D F$ degrees of freedom, $M S$ means squares, $F p r$ F probability, TTN total tuber number per hectare; $P S T T N$ percent of symptomatic tubers ( $\%$ of total tuber number per hectare); TTW total tuber weight (ton ha ${ }^{-1}$ ), PSTTW percent of symptomatic tubers ( $\%$ of total tuber weight in ton ha ${ }^{-1}$ ); $P W T T W$ percent of ware sized tubers ( $\%$ of total tuber weight in ton $\mathrm{ha}^{-1}$ )

$*$ =significant at $P \leq 0.05$

sample (Priou et al. 1999). The composite sample was then analyzed for latent infection using the post-enrichment enzyme-linked immunosorbent assay on nitrocellulose membrane (NCM-ELISA) test as described by Priou et al. (1999).

\section{Data analysis}

Data on soil bacterial count (SBC), days to onset of wilting (DTOW), final BWI, total tuber numbers (TTN), total tuber weight in tons ha ${ }^{-1}$ (TTW), proportion of symptomatic tubers based on total tuber numbers (PSTTN), proportion of symptomatic tubers based on total tuber weight (PSTTW), and proportion of ware sized tubers based on total tuber weight (PWTTW) values were subjected to analysis of variance using Genstat statistical package, 14th edition (Payne et al. 2011). Data on TTN, TTW, PWTTW, PSTTN and PSTTW were first averaged on plot basis; the average value was then used to extrapolate values per hectare. The total tuber weight (TTW) was given in tons/ha. Where analysis of variance showed significant differences, mean separation was done using Fisher's protected LSD (Steel and Torrie 1980). Data on latent infection (LI) level were subjected to Kruskal-Wallis nonparametric test procedure using SPSS for Windows Release Version 18.0 (SPSS Inc., 2009). Data for different seasons were analysed separately. Potato genotypes were also ranked based on \% latent infection (\% LI), final BWI, DTOW, TTN, TTW, PWTTW, PSTTW and PSTTN. Resistance of geneotypes to bacterial wilt was determined using ranking based on \% LI, final BWI, DTOW, PSTTW and PSTTN.

\section{Results}

\section{Weather Data}

The second season experienced much higher rainfall and slightly lower temperatures than the first season (Table 2). This was expected because the second season coincided with the long rains season (March-June) while the first season coincided with the short rains season (October-December). The third season experienced much higher temperatures than the first two.

\section{Soil Bacterial Counts}

There were significant differences $(P \leq 0.05)$ in soil bacterial counts between seasons, among sampling times and in the seasons $\mathrm{x}$ sampling time interaction (Table 3 ). The third season had the highest number of soil bacteria counts followed by the second season while the first season had the least (Table 4).

\section{Bacterial Wilt Incidence and Days to Onset of Wilting}

The final BWI was significantly different among potato genotypes in the first and second seasons while DTOW was significant in the first and third seasons (Table 5). For most genotypes, percent wilting increased rapidly from 60 days after planting and levelled off at 90-100 days after planting (Figs. 1, 2 and 3). The highest final BWI (indicated by \% of wilted plants) in the first season was in genotype Tigoni 
Table 8 Mean response and ranks among 36 potato genotypes for agronomic traits" during the first season

\begin{tabular}{|c|c|c|c|c|c|c|c|c|c|c|c|c|c|c|}
\hline \multirow[t]{2}{*}{ GENOTYPE } & \multicolumn{2}{|c|}{ DTOW } & \multicolumn{2}{|c|}{ PWTTW } & \multicolumn{2}{|l|}{ TTW } & \multicolumn{2}{|c|}{ PSTTW } & \multicolumn{2}{|l|}{ TTN } & \multicolumn{2}{|c|}{ PSTTN } & \multicolumn{2}{|c|}{ FINAL BWI } \\
\hline & Mean & Rank & Mean & Rank & Mean & Rank & Mean & Rank & Mean & Rank & Mean & Rank & Mean & Ran \\
\hline Kenya Baraka & 60.0 & 1.0 & 30.0 & 7.0 & 39.7 & 12.5 & 29.6 & 4.0 & 330861 & 8.0 & 33.3 & 6.0 & 23.33 & 5.5 \\
\hline Tigoni Long & 56.7 & 4.0 & 22.7 & 20.5 & 37.0 & 24.0 & 37.8 & 21.5 & 31851 & 36.0 & 31.4 & 4.0 & 40.00 & 30.0 \\
\hline Kenya Mavuno & 56.7 & 4.0 & 19.8 & 31.0 & 41.3 & 9.5 & 33.6 & 12.0 & 335799 & 6.0 & 30.5 & 3.0 & 28.33 & 18.0 \\
\hline Sterling & 56.7 & 4.0 & 22.9 & 19.0 & 33.3 & 31.0 & 50.7 & 32.0 & 224689 & 34.0 & 46.9 & 32.0 & 30.00 & 21.5 \\
\hline 393385.57 & 56.7 & 4.0 & 21.5 & 25.0 & 38.7 & 17.0 & 38.3 & 23.0 & 325923 & 9.0 & 36.5 & 9.5 & 25.00 & 9.5 \\
\hline Meru & 56.7 & 4.0 & 34.5 & 2.0 & 41.3 & 9.5 & 31.7 & 8.0 & 308639 & 15.5 & 36.5 & 9.5 & 31.67 & 24.0 \\
\hline 394905.8 & 54.1 & 7.0 & 23.0 & 18.0 & 29.8 & 34.0 & 35.8 & 17.0 & 224694 & 33.0 & 40.0 & 19.5 & 30.78 & 23.0 \\
\hline Kihoro & 53.3 & 10.0 & 26.0 & 11.0 & 47.0 & 3.0 & 39.9 & 26.0 & 358021 & 3.0 & 43.8 & 29.0 & 45.00 & 32.5 \\
\hline 394903.3 & 53.3 & 10.0 & 28.7 & 9.0 & 52.3 & 1.0 & 30.1 & 5.0 & 437033 & 1.0 & 36.1 & 7.0 & 25.00 & 9.5 \\
\hline 394906.6 & 53.3 & 10.0 & 20.4 & 29.0 & 29.7 & 35.0 & 52.3 & 33.0 & 234566 & 31.5 & 50.8 & 33.0 & 23.33 & 5.5 \\
\hline Nyayo & 53.3 & 10.0 & 21.5 & 25.0 & 37.3 & 22.5 & 32.9 & 9.0 & 348144 & 4.0 & 36.9 & 13.0 & 35.00 & 27.5 \\
\hline Asante & 53.3 & 10.0 & 22.7 & 20.5 & 37.3 & 22.5 & 37.4 & 18.0 & 264195 & 24.0 & 52.8 & 34.0 & 33.33 & 25.5 \\
\hline Desiree & 50.0 & 14.5 & 33.0 & 5.0 & 33.3 & 31.0 & 30.5 & 6.5 & 259257 & 26.0 & 32.3 & 5.0 & 25.00 & 9.5 \\
\hline Kenya Sifa & 50.0 & 14.5 & 22.2 & 23.0 & 39.3 & 14.5 & 20.9 & 2.0 & 338268 & 5.0 & 29.7 & 2.0 & 23.33 & 5.5 \\
\hline Purple Gold & 50.0 & 14.5 & 23.4 & 16.0 & 38.3 & 19.5 & 37.8 & 21.5 & 298763 & 19.0 & 36.5 & 9.5 & 30.00 & 21.5 \\
\hline Sherekea & 50.0 & 14.5 & 23.1 & 17.0 & 31.7 & 33.0 & 30.5 & 6.5 & 256787 & 28.0 & 45.1 & 30.5 & 28.33 & 18.0 \\
\hline 394034.7 & 47.3 & 17.0 & 23.8 & 15.0 & 38.5 & 18.0 & 37.7 & 19.5 & 295677 & 20.0 & 40.0 & 19.5 & 2.56 & 1.0 \\
\hline 396286.6 & 46.7 & 18.0 & 20.0 & 30.0 & 28.4 & 36.0 & 54.5 & 34.0 & 178266 & 35.0 & 54.0 & 36.0 & 17.49 & 2.0 \\
\hline B53 & 46.7 & 19.5 & 24.2 & 14.0 & 43.7 & 6.0 & 47.6 & 31.0 & 311108 & 13.5 & 41.0 & 26.0 & 23.33 & 5.5 \\
\hline Kenya Furaha & 46.7 & 19.5 & 30.7 & 6.0 & 43.3 & 7.0 & 35.1 & 15.0 & 316046 & 10.5 & 38.5 & 14.0 & 28.33 & 18.0 \\
\hline Kenya Mpya & 43.3 & 23.5 & 21.2 & 25.0 & 36.7 & 25.0 & 37.7 & 19.5 & 256788 & 27.0 & 40.2 & 21.5 & 28.33 & 18.0 \\
\hline Saturna & 43.3 & 23.5 & 20.6 & 27.5 & 33.7 & 28.5 & 34.1 & 13.0 & 274071 & 23.0 & 40.7 & 23.0 & 50.00 & 35.0 \\
\hline Kerr's Pink & 43.3 & 23.5 & 17.0 & 33.0 & 44.0 & 5.0 & 33.4 & 11.0 & 333330 & 7.0 & 43.1 & 27.5 & 28.33 & 18.0 \\
\hline Bishop Gitonga & 43.3 & 23.5 & 22.6 & 22.0 & 39.0 & 16.0 & 26.2 & 3.0 & 313577 & 12.0 & 40.9 & 24.5 & 50.00 & 35.0 \\
\hline Arka & 43.3 & 23.5 & 28.3 & 10.0 & 38.3 & 19.5 & 39.6 & 25.0 & 293824 & 21.0 & 43.1 & 27.5 & 21.67 & 3.0 \\
\hline Roslin Tana & 43.3 & 23.5 & 25.4 & 13.0 & 40.0 & 11.0 & 34.7 & 14.0 & 303701 & 18.0 & 40.9 & 24.5 & 26.67 & 13.5 \\
\hline 394904.17 & 40.0 & 30.0 & 29.6 & 8.0 & 33.3 & 31.0 & 43.2 & 29.0 & 254319 & 29.0 & 40.2 & 21.5 & 26.67 & 13.5 \\
\hline Pimpernel & 40.0 & 30.0 & 35.5 & 1.0 & 44.7 & 4.0 & 40.2 & 27.0 & 288886 & 22.0 & 39.7 & 18.0 & 45.00 & 32.5 \\
\hline Annete & 40.0 & 30.0 & 33.2 & 4.0 & 35.7 & 28.5 & 40.5 & 28.0 & 261726 & 25.0 & 53.2 & 35.0 & 35.00 & 27.5 \\
\hline Ingabire & 40.0 & 30.0 & 13.3 & 34.0 & 41.7 & 8.0 & 33.0 & 10.0 & 308639 & 15.5 & 36.5 & 9.5 & 25.00 & 9.5 \\
\hline Dutch Robyjn & 40.0 & 30.0 & 12.6 & 35.0 & 39.7 & 12.5 & 43.4 & 30.0 & 316046 & 10.5 & 39.3 & 17.0 & 38.33 & 29.0 \\
\hline Tigoni & 40.0 & 30.0 & 25.7 & 12.0 & 39.3 & 14.5 & 38.4 & 24.0 & 311108 & 13.5 & 39.0 & 16.0 & 55.00 & 35.0 \\
\hline Ngure & 40.0 & 30.0 & 18.2 & 32.0 & 36.3 & 26.0 & 57.9 & 36.0 & 306170 & 17.0 & 38.8 & 15.0 & 26.67 & 13.5 \\
\hline 387164.4 & 36.8 & 34.0 & 5.5 & 36.0 & 48.3 & 2.0 & 20.7 & 1.0 & 385243 & 2.0 & 29.4 & 1.0 & 42.44 & 31.0 \\
\hline Roslin Bvumbwe & 36.7 & 35.5 & 34.1 & 3.0 & 37.7 & 21.0 & 35.5 & 16.0 & 237035 & 30.0 & 36.8 & 12.0 & 33.33 & 25.5 \\
\hline 394895.7 & 36.7 & 35.5 & 20.6 & 27.5 & 36.0 & 27.0 & 54.7 & 35.0 & 234566 & 31.5 & 45.1 & 30.5 & 26.67 & 13.5 \\
\hline Mean & 47.26 & & 23.82 & & 38.49 & & 37.70 & & 295674 & & 40.00 & & 30.79 & \\
\hline $\operatorname{LSD}(0.05)$ & 14.10 & & 16.44 & & 10.73 & & 19.28 & & 78914.1 & & 16.90 & & 14.17 & \\
\hline SED & 7.07 & & 8.24 & & 5.38 & & 9.66 & & 39567.1 & & 8.47 & & 7.10 & \\
\hline$\% \mathrm{CV}$ & 18.30 & & 42.4 & & 17.1 & & 31.40 & & 16.4 & & 26.00 & & 28.30 & \\
\hline
\end{tabular}

DTOW days to onset of wilting, FINAL BWI bacterial wilt incidence at 120 days after planting, PWTTW proportion of ware sized tubers (\% of total tuber weight in ton $\mathrm{ha}^{-1}$ ), TTW total tuber weight (ton $\mathrm{ha}^{-1}$ ), TTN total tuber number per hectare, PSTTW proportion of symptomatic tubers (\% of total tuber weight in ton $\mathrm{ha}^{-1}$ ), PSTTN proportion of symptomatic tubers ( $\%$ of total tuber number per hectare)

followed by Saturna, Pimpernel, Bishop Gitonga and Kihoro in that order. In the second season, final BWI was highest in Kerr's Pink followed by Dutch Robyjn while Cangi was third
(Fig. 2). In both seasons, the latest clones from the International Potato Centre had the lowest BWI: clones 394905.8 and 387164.4 had the lowest BWI in the second season while 
Table 9 Mean response and ranks among 36 potato genotypes for agronomic traits during the second season

\begin{tabular}{|c|c|c|c|c|c|c|c|c|c|c|c|c|c|c|}
\hline \multirow[t]{2}{*}{ GENOTYPE } & \multicolumn{2}{|c|}{ FINALBWI } & \multicolumn{2}{|c|}{ DTOW } & \multicolumn{2}{|l|}{ TTW } & \multicolumn{2}{|l|}{ TTN } & \multicolumn{2}{|c|}{ PWTTW } & \multicolumn{2}{|c|}{ PSTTW } & \multicolumn{2}{|c|}{ PSTTN } \\
\hline & Mean & Rank & Mean & Rank & Mean & Rank & Mean & Rank & Mean & Rank & Mean & Rank & Mean & Rank \\
\hline Sherekea & 30.00 & 18.5 & 60.00 & 1.0 & 63.3 & 8.5 & 513575 & 1.0 & 28.9 & 27.0 & 49.8 & 22.0 & 56.2 & 23.0 \\
\hline 394905.8 & 18.33 & 1.0 & 59.61 & 2.5 & 51.5 & 29.0 & 440374 & 13.0 & 14.1 & 36.0 & 70.0 & 36.0 & 70.6 & 34.0 \\
\hline 387164.4 & 20.00 & 2.0 & 59.61 & 2.5 & 45.5 & 36.0 & 351510 & 32.0 & 25.6 & 29.0 & 59.7 & 32.0 & 61.8 & 30.0 \\
\hline Roslin Tana & 38.33 & 26.0 & 56.67 & 7.5 & 55.7 & 22.5 & 370367 & 26.0 & 38.8 & 12.0 & 42.7 & 10.5 & 49.5 & 15.0 \\
\hline Pimpernel & 26.67 & 8.5 & 56.67 & 7.5 & 47.7 & 35.0 & 286417 & 36.0 & 21.1 & 34.0 & 60.4 & 34.0 & 68.5 & 33.0 \\
\hline Kerr's Pink & 46.67 & 34.0 & 56.67 & 7.5 & 62.0 & 11.0 & 429625 & 17.0 & 38.7 & 13.0 & 50.7 & 23.0 & 57.5 & 25.5 \\
\hline Tigoni & 36.67 & 23.5 & 56.67 & 7.5 & 53.0 & 27.0 & 439502 & 14.0 & 19.1 & 35.0 & 69.4 & 35.0 & 71.6 & 35.0 \\
\hline Bishop Gitonga & 43.33 & 30.5 & 56.67 & 7.5 & 69.7 & 3.5 & 474069 & 5.0 & 38.1 & 14.0 & 54.0 & 26.0 & 54.0 & 20.0 \\
\hline Annete & 23.33 & 4.0 & 56.67 & 7.5 & 61.0 & 12.0 & 454316 & 8.5 & 31.2 & 22.0 & 56.1 & 28.0 & 55.9 & 22.0 \\
\hline 394034.7 & 23.33 & 4.0 & 56.67 & 7.5 & 60.7 & 13.0 & 459255 & 6.0 & 22.0 & 32.0 & 54.3 & 27.0 & 52.4 & 18.0 \\
\hline 393382.44 & 36.67 & 23.5 & 56.67 & 7.5 & 54.0 & 26.0 & 345676 & 34.0 & 40.8 & 9.0 & 40.5 & 8.0 & 47.6 & 10.0 \\
\hline Sterling & 40.00 & 28.5 & 53.33 & 16.0 & 51.3 & 30.0 & 353083 & 30.0 & 40.0 & 11.0 & 40.3 & 7.0 & 42.6 & 3.0 \\
\hline Purple Gold & 26.67 & 8.5 & 53.33 & 16.0 & 59.0 & 18.0 & 449378 & 11.0 & 29.0 & 26.0 & 57.3 & 29.0 & 60.5 & 29.0 \\
\hline Nyayo & 30.00 & 18.5 & 53.33 & 16.0 & 63.3 & 8.5 & 451847 & 10.0 & 44.1 & 4.0 & 46.7 & 18.0 & 50.3 & 16.0 \\
\hline Kihoro & 30.00 & 18.5 & 53.33 & 16.0 & 57.7 & 19.5 & 410490 & 19.0 & 34.2 & 17.0 & 43.5 & 13.0 & 46.2 & 9.0 \\
\hline Kenya Sifa & 30.00 & 18.5 & 53.33 & 16.0 & 69.3 & 5.0 & 385181 & 25.0 & 60.8 & 1.0 & 33.6 & 2.0 & 43.2 & 5.5 \\
\hline Kenya Mpya & 46.67 & 34.0 & 53.33 & 16.0 & 65.7 & 6.0 & 488884 & 4.0 & 31.4 & 21.0 & 47.2 & 19.0 & 48.8 & 13.0 \\
\hline Kenya Mavuno & 26.67 & 8.5 & 53.33 & 16.0 & 63.0 & 10.0 & 454316 & 8.5 & 28.0 & 28.0 & 49.2 & 21.0 & 58.0 & 27.0 \\
\hline Roslin Bvumbwe & 33.33 & 21.0 & 53.33 & 16.0 & 78.0 & 1.0 & 490859 & 3.0 & 47.0 & 2.0 & 34.6 & 4.0 & 41.8 & 2.0 \\
\hline 394895.7 & 35.00 & 22.0 & 53.33 & 16.0 & 55.3 & 24.0 & 330861 & 35.0 & 45.9 & 3.0 & 38.7 & 6.0 & 44.3 & 7.0 \\
\hline Kenya Karibu & 26.67 & 8.5 & 50.00 & 26.5 & 57.7 & 19.5 & 429626 & 16.0 & 35.8 & 15.0 & 42.7 & 10.5 & 47.7 & 11.0 \\
\hline Romano & 28.33 & 14.0 & 50.00 & 26.5 & 50.3 & 32.0 & 370366 & 27.0 & 31.1 & 23.0 & 44.3 & 15.0 & 53.5 & 19.0 \\
\hline Kenya Baraka & 28.33 & 14.0 & 50.00 & 26.5 & 71.3 & 2.0 & 498760 & 2.0 & 33.9 & 19.0 & 57.5 & 30.0 & 57.5 & 25.5 \\
\hline Ingabire & 28.33 & 14.0 & 50.00 & 26.5 & 59.7 & 16.0 & 385675 & 24.0 & 43.7 & 5.0 & 31.7 & 1.0 & 38.0 & 1.0 \\
\hline Dutch Robyjn & 45.00 & 32.0 & 50.00 & 26.5 & 69.7 & 3.5 & 351757 & 31.0 & 41.5 & 8.0 & 35.3 & 5.0 & 44.7 & 8.0 \\
\hline Desiree & 38.33 & 26.0 & 50.00 & 26.5 & 54.7 & 25.0 & 358021 & 28.5 & 40.1 & 10.0 & 42.9 & 12.0 & 48.6 & 12.0 \\
\hline Cangi & 43.33 & 30.5 & 50.00 & 26.5 & 55.7 & 22.5 & 404934 & 20.5 & 25.2 & 30.0 & 58.5 & 31.0 & 57.2 & 24.0 \\
\hline B53 & 46.67 & 34.0 & 50.00 & 26.5 & 64.0 & 7.0 & 444440 & 12.0 & 32.2 & 20.0 & 44.0 & 14.0 & 42.9 & 4.0 \\
\hline 396286.6 & 28.33 & 14.0 & 50.00 & 26.5 & 48.7 & 34.0 & 404934 & 20.5 & 23.9 & 31.0 & 60.1 & 33.0 & 72.9 & 36.0 \\
\hline 394906.6 & 48.33 & 36.0 & 50.00 & 26.5 & 56.3 & 21.0 & 422218 & 18.0 & 34.4 & 16.0 & 52.9 & 25.0 & 65.8 & 32.0 \\
\hline 394903.3 & 26.67 & 8.5 & 50.00 & 26.5 & 50.7 & 31.0 & 392589 & 22.0 & 30.6 & 24.0 & 52.8 & 24.0 & 61.9 & 31.0 \\
\hline 393385.57 & 38.33 & 26.0 & 50.00 & 26.5 & 60.0 & 15.0 & 358021 & 28.5 & 43.4 & 6.0 & 34.3 & 3.0 & 43.2 & 5.5 \\
\hline Meru & 40.00 & 28.5 & 46.67 & 34.0 & 49.7 & 33.0 & 350614 & 33.0 & 21.3 & 33.0 & 45.8 & 16.0 & 52.2 & 17.0 \\
\hline Asante & 26.67 & 8.5 & 46.67 & 34.0 & 59.3 & 17.0 & 434564 & 15.0 & 42.3 & 7.0 & 46.6 & 17.0 & 55.0 & 21.0 \\
\hline Arka & 28.33 & 14.0 & 46.67 & 34.0 & 52.7 & 28.0 & 387650 & 23.0 & 34.1 & 18.0 & 40.6 & 9.0 & 49.3 & 14.0 \\
\hline 394904.17 & 23.33 & 4.0 & 43.33 & 36.0 & 60.3 & 14.0 & 456785 & 7.0 & 29.9 & 25.0 & 48.5 & 20.0 & 59.8 & 28.0 \\
\hline Mean & & & 52.66 & & 58.50 & & 411959 & & 34.00 & & 48.50 & & 53.70 & \\
\hline $\operatorname{LSD}(0.05)$ & & & 12.49 & & 21.42 & & 159460.80 & & 23.74 & & 23.74 & & 21.85 & \\
\hline SED & & & 6.26 & & 10.74 & & 79952.80 & & 11.90 & & 11.90 & & 10.96 & \\
\hline$\% \mathrm{CV}$ & & & 14.60 & & 22.80 & & 23.50 & & 42.90 & & 30.20 & & 25.00 & \\
\hline
\end{tabular}

DTOW days to onset of wilting, FINAL BWI bacterial wilt incidence at 120 days after planting, PWTTW proportion of ware sized tubers (\% of total tuber weight in ton ha ${ }^{-1}$ ), TTW total tuber weight (ton $\left.\mathrm{ha}^{-1}\right), T T N$ total tuber number per hectare, $P S T T W$ proportion of symptomatic tubers $(\%$ of total tuber weight in ton $\mathrm{ha}^{-1}$ ), PSTTN proportion of symptomatic tubers ( $\%$ of total tuber number per hectare)

clones 396286.6, 394906.6 and 393385.57 had low BWI in the first season. In addition, cultivars Arka and Kenya Baraka had low BWI in the first season (Fig. 1). In the third season, however, final BWI was highest in clone 394895.7 followed by clone 394906.6, then sherekea while Kihoro was fourth (Fig. 3). In the same season, clone 394904.17 had the least 
Table 10 Mean response and ranks among 36 potato genotypes for agronomic traits" during the third season

\begin{tabular}{|c|c|c|c|c|c|c|c|c|c|c|c|c|c|c|}
\hline \multirow[t]{2}{*}{ GENOTYPE } & \multicolumn{2}{|c|}{ FINAL BWI } & \multicolumn{2}{|l|}{ DTOW } & \multicolumn{2}{|c|}{ PWTTW } & \multicolumn{2}{|l|}{ PSTTW } & \multicolumn{2}{|l|}{ TTW } & \multicolumn{2}{|l|}{ TTN } & \multicolumn{2}{|l|}{ PSTTN } \\
\hline & MEAN & RANK & MEAN & RANK & MEAN & RANK & MEAN & RANK & MEAN & RANK & MEAN & RANK & MEAN & RANK \\
\hline Ingabire & 51.0 & 9.0 & 60 & 2.5 & 62.20 & 1.0 & 25.9 & 5 & 73.00 & 1.0 & 404942 & 23 & 20.6 & 3 \\
\hline Kenya Sifa & 25.3 & 2.0 & 57 & 5.0 & 60.40 & 2.0 & 16.7 & 3 & 60.67 & 5.0 & 394646 & 26 & 22.3 & 4 \\
\hline Kenya Baraka & 34.3 & 4.0 & 60 & 2.5 & 55.60 & 3.0 & 11.6 & 2 & 66.33 & 2.0 & 496485 & 4 & 19.8 & 2 \\
\hline 394906.6 & 87.7 & 35.0 & 50 & 13.5 & 47.80 & 4.0 & 27.7 & 8 & 53.67 & 14.5 & 426898 & 19 & 31.7 & 11 \\
\hline 394034.7 & 67.3 & 19.0 & 53 & 9.0 & 46.30 & 5.0 & 29.2 & 9 & 54.33 & 12.0 & 452789 & 12 & 36.4 & 12 \\
\hline 393382.44 & 45.7 & 7.0 & 53 & 9.0 & 44.00 & 6.0 & 31.0 & 10 & 47.33 & 23.5 & 343090 & 35 & 38.3 & 13 \\
\hline Kenya Karibu & 31.3 & 3.0 & 67 & 1.0 & 43.70 & 7.0 & 11.4 & 1 & 53.00 & 17.0 & 465156 & 9 & 14.8 & 1 \\
\hline 393385.57 & 42.0 & 6.0 & 43 & 20.0 & 41.70 & 8.0 & 25.7 & 4 & 54.67 & 11.0 & 397541 & 24 & 27.9 & 7 \\
\hline Roslin Bvumbwe & 35.7 & 5.0 & 40 & 25.5 & 39.70 & 9.0 & 37.0 & 15 & 58.33 & 8.0 & 490088 & 5 & 41.2 & 15 \\
\hline 394895.7 & 91.3 & 36.0 & 43 & 20.0 & 38.40 & 10.0 & 35.2 & 14 & 49.33 & 21.0 & 365827 & 30 & 29.6 & 8 \\
\hline 394903.3 & 68.0 & 20.0 & 53 & 9.0 & 36.60 & 11.0 & 27.5 & 7 & 46.67 & 25.5 & 394521 & 27 & 46.3 & 20 \\
\hline 396286.6 & 72.3 & 23.0 & 47 & 16.5 & 33.70 & 12.5 & 26.0 & 6 & 46.33 & 27.5 & 413858 & 21 & 31.6 & 10 \\
\hline Sterling & 60.0 & 12.0 & 50 & 13.5 & 33.70 & 12.5 & 53.8 & 32 & 47.33 & 23.5 & 357842 & 32 & 45.8 & 19 \\
\hline 394905.8 & 83.3 & 33.0 & 50 & 13.5 & 33.30 & 14.0 & 32.7 & 11 & 46.67 & 25.5 & 427670 & 18 & 24.8 & 6 \\
\hline Annete & 63.3 & 15.5 & 37 & 30.0 & 33.10 & 15.0 & 35.0 & 13 & 53.67 & 14.5 & 473686 & 8 & 54.8 & 29 \\
\hline Kenya Mavuno & 78.3 & 28.0 & 43 & 20.0 & 31.80 & 16.0 & 47.8 & 20 & 59.33 & 6.0 & 456580 & 11 & 51.4 & 26 \\
\hline Nyayo & 63.3 & 15.5 & 40 & 25.5 & 31.40 & 17.0 & 49.9 & 24 & 41.33 & 34.0 & 440923 & 15 & 60.6 & 32 \\
\hline 394904.17 & 22.7 & 1.0 & 53 & 9.0 & 30.80 & 18.0 & 33.9 & 12 & 52.67 & 18.0 & 443887 & 14 & 24.4 & 5 \\
\hline Romano & 69.3 & 22.0 & 47 & 16.5 & 30.30 & 19.0 & 45.3 & 19 & 36.67 & 36.0 & 375242 & 29 & 52.8 & 27 \\
\hline Asante & 61.0 & 14.0 & 40 & 25.5 & 30.20 & 20.0 & 59.0 & 35 & 56.00 & 10.0 & 459900 & 10 & 44 & 16 \\
\hline Kenya Mpya & 65.0 & 17.0 & 43 & 20.0 & 29.30 & 21.0 & 49.5 & 23 & 62.00 & 3.0 & 511682 & 3 & 48.9 & 21 \\
\hline Kerr's Pink & 74.3 & 24.0 & 37 & 30.0 & 28.80 & 22.0 & 42.6 & 17 & 53.67 & 14.5 & 433481 & 17 & 49.3 & 23 \\
\hline Kihoro & 76.3 & 26.0 & 33 & 33.5 & 27.30 & 23.0 & 52.4 & 30 & 45.00 & 29.0 & 422287 & 20 & 69 & 35 \\
\hline Sherekea & 87.3 & 34.0 & 50 & 13.5 & 26.40 & 24.0 & 51.3 & 26 & 57.00 & 9.0 & 519960 & 1 & 40.8 & 14 \\
\hline Tigoni & 58.3 & 11.0 & 33 & 33.5 & 25.80 & 25.0 & 50.9 & 25 & 52.00 & 19.0 & 514773 & 2 & 71.8 & 36 \\
\hline Arka & 60.7 & 13.0 & 53 & 9.0 & 25.60 & 26.0 & 43.6 & 18 & 46.33 & 27.5 & 396743 & 25 & 49.7 & 24 \\
\hline Desiree & 67.0 & 18.0 & 43 & 20.0 & 25.40 & 27.0 & 48.3 & 21 & 41.00 & 35.0 & 363547 & 31 & 44.4 & 17 \\
\hline B53 & 82.7 & 32.0 & 57 & 5.0 & 25.30 & 28.0 & 52.2 & 28.5 & 53.67 & 14.5 & 433996 & 16 & 45.7 & 18 \\
\hline Meru & 69.0 & 21.0 & 40 & 25.5 & 24.70 & 29.0 & 39.1 & 16 & 43.33 & 31.5 & 355682 & 33 & 53.3 & 28 \\
\hline 387164.4 & 53.7 & 10.0 & 57 & 5.0 & 24.10 & 30.0 & 49.0 & 22 & 44.00 & 30.0 & 344817 & 34 & 30.7 & 9 \\
\hline Roslin Tana & 80.7 & 31.0 & 33 & 33.5 & 24.00 & 31.0 & 57.0 & 34 & 42.67 & 33.0 & 379220 & 28 & 49.8 & 25 \\
\hline Cangi & 79.3 & 29.0 & 37 & 30.0 & 23.90 & 32.0 & 52.2 & 28.5 & 50.67 & 20.0 & 406765 & 22 & 49.2 & 22 \\
\hline Pimoernel & 50.7 & 8.0 & 40 & 25.5 & 23.60 & 33.0 & 51.7 & 27 & 43.33 & 31.5 & 288855 & 36 & 64.1 & 34 \\
\hline Purple Gold & 79.7 & 30.0 & 33 & 33.5 & 22.90 & 34.0 & 53.8 & 31 & 48.00 & 22.0 & 446832 & 13 & 62.8 & 33 \\
\hline Bishop Gitonga & 77.3 & 27.0 & 40 & 25.5 & 21.60 & 35.0 & 56.2 & 33 & 61.67 & 4.0 & 477053 & 7 & 60.1 & 31 \\
\hline Dutch Robyjn & 74.7 & 25.0 & 30 & 36.0 & 19.70 & 36.0 & 66.9 & 36 & 58.67 & 7.0 & 487847 & 6 & 58.9 & 30 \\
\hline Mean & 63.6 & & 45.74 & & 33.40 & & 41.1 & & 51.68 & & 424031 & & 43.50 & \\
\hline LSD (0.05) & 41.0 & & 13.32 & & 23.53 & & 22.3 & & 16.32 & & 130343.6 & & 20.02 & \\
\hline SED & 20.6 & & 6.68 & & 11.80 & & 11.2 & & 8.18 & & 65353.6 & & 10.04 & \\
\hline$\% \mathrm{CV}$ & 39.6 & & 17.90 & & 43.20 & & 33.4 & & 19.40 & & 18.9 & & 28.20 & \\
\hline
\end{tabular}

DTOW days to onset of wilting, FINAL BWI bacterial wilt incidence at 120 days after planting, $P$ WTTW proportion of ware sized tubers (\% of total tuber weight in ton ha ${ }^{-1}$ ), TTW total tuber weight (ton $\left.\mathrm{ha}^{-1}\right), T T N$ total tuber number per hectare, $P S T T W$ proportion of symptomatic tubers $(\%$ of total tuber weight in ton $\mathrm{ha}^{-1}$ ), PSTTN proportion of symptomatic tubers ( $\%$ of total tuber number per hectare)

final BWI followed by Kenya Sifa then Kenya Karibu and Kenya Baraka in that order while Roslin Bvumbwe was the fifth. In the third season, many genotypes had higher final BWI than in the first two seasons. 
Table 11 Overall ranking of the genotypes in the three seasons

\begin{tabular}{|c|c|c|c|c|c|c|}
\hline \multirow[t]{2}{*}{ Genotype } & \multicolumn{2}{|l|}{ First season } & \multicolumn{2}{|l|}{ Second season } & \multicolumn{2}{|l|}{ Third season } \\
\hline & Sum of ranks & Overall rank & Sum of ranks & Overall rank & Sum of ranks & Overall rank \\
\hline Kenya Baraka & 59.5 & 1 & 179 & 26 & 21.5 & 1 \\
\hline Tigoni Long & 143.5 & 16 & & & & \\
\hline Kenya Mavuno & 104 & 4 & 139 & 13 & 133.0 & 14 \\
\hline Sterling & 194 & 30 & 145.5 & 14 & 160.5 & 22 \\
\hline 393385.57 & 125.5 & 10 & 170.5 & 22 & 100.5 & 7 \\
\hline Meru & 107 & 6 & 201.2 & 31 & 220.0 & 33 \\
\hline 394905.8 & 180 & 29 & 201.5 & 32 & 129.5 & 12.5 \\
\hline Kihoro & 122.5 & 8 & 132 & 9 & 224.5 & 34 \\
\hline 394903.3 & 71 & 3 & 193.7 & 28 & 134.5 & 15 \\
\hline 394906.6 & 197.5 & 31 & 221.2 & 34 & 123.5 & 9 \\
\hline Nyayo & 131.5 & 12 & 124.3 & 8 & 194.0 & 28 \\
\hline Kenya Sifa & 70 & 2 & 113 & 4 & 51.0 & 4 \\
\hline Desiree & 105.5 & 5 & 170 & 21 & 180.5 & 25.5 \\
\hline Asante & 167.5 & 24 & 135.5 & 12 & 142.0 & 16.5 \\
\hline Purple Gold & 142 & 15 & 170.8 & 23 & 227.5 & 35 \\
\hline Sherekea & 176 & 28 & 134.3 & 11 & 142.0 & 16.5 \\
\hline 394034.7 & 111 & 7 & 134.2 & 10 & 86.5 & 6 \\
\hline 396286.6 & 199 & 33 & 235 & 36 & 129.5 & 12.5 \\
\hline B53 & 128.5 & 11 & 150.8 & 17 & 169.0 & 23 \\
\hline Kenya Furaha & 124.5 & 9 & & & & \\
\hline Kenya Mpya & 172.5 & 27 & 146.3 & 15.5 & 125.0 & 10 \\
\hline Saturna & 202 & 34 & & & & \\
\hline Kerr's Pink & 145.5 & 19 & 171 & 24 & 180.5 & 25.5 \\
\hline Bishop Gitonga & 144 & 17 & 113.2 & 5 & 197.5 & 29 \\
\hline Arka & 158 & 23 & 160 & 18 & 151.0 & 20 \\
\hline Roslin Tana & 138 & 14 & 166.2 & 20 & 246.5 & 36 \\
\hline 394904.17 & 170 & 25 & 174 & 25 & 85.5 & 5 \\
\hline Pimpernel & 150 & 21 & 228 & 35 & 219.5 & 32 \\
\hline Annete & 198.5 & 32 & 124 & 7 & 149.5 & 19 \\
\hline Ingabire & 145 & 18 & 107.5 & 3 & 47.5 & 3 \\
\hline Dutch Robyjn & 172 & 26 & 114 & 6 & 210.0 & 31 \\
\hline Tigoni & 147 & 20 & 197 & 29 & 176.0 & 24 \\
\hline Ngure & 204 & 35 & & & & \\
\hline 387164.4 & 135.5 & 13 & 203.5 & 33 & 145.0 & 18 \\
\hline Roslin Bvumbwe & 151 & 22 & 95.7 & 1 & 111.5 & 8 \\
\hline 394895.7 & 235 & 36 & 146.3 & 15.5 & 153.0 & 21 \\
\hline 393382.44 & & & 164.7 & 19 & 128.0 & 11 \\
\hline Romano & & & 189.8 & 27 & 187.0 & 27 \\
\hline Kenya Karibu & & & 107 & 2 & 40.0 & 2 \\
\hline Cangi & & & 198.3 & 30 & 205.5 & 30 \\
\hline
\end{tabular}

Latent Infection

There were significant differences $(P \leq 0.05)$ among genotypes for latent infection (chi square $=67.72$ ). The mean \% LI was higher in the first season than in the other two seasons (Table 6).
Tuber Yield Traits

Genotypes exhibited significant differences $(P \leq 0.05)$ in total tuber number per hectare (TTN) and total tuber weight (TTW) (tons $\mathrm{ha}^{-1}$ ) in the first season (Table 7). Proportion of symptomatic tubers (PSTTN and PSTTW) as well as proportion of 
Table 12 Ranking for bacterial wilt resistance in the first season

\begin{tabular}{|c|c|c|c|c|c|c|c|}
\hline GENOTYPE & Rank (DTOW) & Rank (PSTTW) & Rank (PSTTN) & Rank (Final BWI) & Rank LI & Average Rank & Overall Rank \\
\hline Kenya Baraka & 1.0 & 4.0 & 6.0 & 5.5 & 16.5 & 6.4 & 2.0 \\
\hline Tigoni Long & 4.0 & 21.5 & 4.0 & 30.0 & 4.5 & 12.6 & 7.0 \\
\hline Kenya Mavuno & 4.0 & 12.0 & 3.0 & 18.0 & 2.0 & 11.5 & 4.0 \\
\hline Sterling & 4.0 & 32.0 & 32.0 & 21.5 & 21.0 & 22.0 & 30.0 \\
\hline 393385.57 & 4.0 & 23.0 & 9.5 & 9.5 & 28.5 & 14.9 & 8.0 \\
\hline Meru & 4.0 & 8.0 & 9.5 & 24.0 & 34.5 & 16.0 & 9.5 \\
\hline 394905.8 & 7.0 & 17.0 & 19.5 & 23.0 & 28.5 & 19.0 & 14.5 \\
\hline Kihoro & 10.0 & 26.0 & 29.0 & 32.5 & 9.0 & 21.1 & 27.0 \\
\hline 394903.3 & 10.0 & 5.0 & 7.0 & 9.5 & 28.5 & 12.0 & 6.0 \\
\hline 394906.6 & 10.0 & 33.0 & 33.0 & 5.5 & 21.0 & 20.4 & 25.5 \\
\hline Nyayo & 10.0 & 9.0 & 13.0 & 27.5 & 21.0 & 16.0 & 9.5 \\
\hline Asante & 10.0 & 18.0 & 34.0 & 25.5 & 14.0 & 20.1 & 22.5 \\
\hline Desiree & 14.5 & 6.5 & 5.0 & 9.5 & 9.0 & 8.7 & 3.0 \\
\hline Kenya Sifa & 14.5 & 2.0 & 2.0 & 5.5 & 4.5 & 5.5 & 1.0 \\
\hline Purple Gold & 14.5 & 21.5 & 9.5 & 21.5 & 21.0 & 17.5 & 11.5 \\
\hline Sherekea & 14.5 & 6.5 & 30.5 & 18.0 & 28.5 & 19.6 & 20.5 \\
\hline 394034.7 & 17.0 & 19.5 & 19.5 & 1.0 & 1.0 & 11.6 & 5.0 \\
\hline 396286.6 & 18.0 & 34.0 & 36.0 & 2.0 & 9.0 & 19.6 & 20.5 \\
\hline B53 & 19.5 & 31.0 & 26.0 & 5.5 & 14.0 & 19.0 & 14.5 \\
\hline Kenya Furaha & 19.5 & 15.0 & 14.0 & 18.0 & 34.5 & 20.2 & 24.0 \\
\hline Kenya Mpya & 23.5 & 19.5 & 21.5 & 18.0 & 14.0 & 19.1 & 16.5 \\
\hline Saturna & 23.5 & 13.0 & 23.0 & 35.0 & 28.5 & 24.6 & 32.5 \\
\hline Kerr's Pink & 23.5 & 11.0 & 27.5 & 18.0 & 21.0 & 20.1 & 22.5 \\
\hline Bishop Gitonga & 23.5 & 3.0 & 24.5 & 35.0 & 9.0 & 18.8 & 13.0 \\
\hline Arka & 23.5 & 25.0 & 27.5 & 3.0 & 28.5 & 21.5 & 29.0 \\
\hline Roslin Tana & 23.5 & 14.0 & 24.5 & 13.5 & 21.0 & 19.2 & 18.0 \\
\hline 394904.17 & 30.0 & 29.0 & 21.5 & 13.5 & 9.0 & 20.4 & 25.5 \\
\hline Pimpernel & 30.0 & 27.0 & 18.0 & 32.5 & 16.5 & 24.6 & 32.5 \\
\hline Annete & 30.0 & 28.0 & 35.0 & 27.5 & 21.0 & 28.2 & 35.0 \\
\hline Ingabire & 30.0 & 10.0 & 9.5 & 9.5 & 28.5 & 17.5 & 11.5 \\
\hline Dutch Robyjn & 30.0 & 30.0 & 17.0 & 29.0 & 9.0 & 22.8 & 31.0 \\
\hline Tigoni & 30.0 & 24.0 & 16.0 & 35.0 & 3.0 & 21.4 & 28.0 \\
\hline Ngure & 30.0 & 36.0 & 15.0 & 13.5 & 34.5 & 25.8 & 34.0 \\
\hline 387164.4 & 34.0 & 1.0 & 1.0 & 31.0 & 28.5 & 19.1 & 16.5 \\
\hline Roslin Bvumbwe & 35.5 & 16.0 & 12.0 & 25.5 & 9.0 & 19.4 & 19.0 \\
\hline 394895.7 & 35.5 & 35.0 & 30.5 & 13.5 & 34.5 & 29.8 & 36.0 \\
\hline
\end{tabular}

ware-sized tubers (PWTTW) were not significant. In the second season, all the five characters were not significant. In the third season, only TTN was not significant (Table 7, Table 8). On average, the second season gave the highest yields (TTW) (Table 9) followed by the third season (Table 10) while the first season had the least (Table 8). The PWTTW followed the same trend.

Ranking of Genotypes Based on Various Traits

When ranking was done based on \% LI, final BWI, DTOW, TTN, TTW, PWTTW, PSTTW, and PSTTN, the top ten genotypes were Kenya Baraka, Kenya Sifa, clone 394903.3, Kenya Mavuno, Desiree, Meru, clone 394034.7, Kihoro, Kenya Furaha and clone 393385.57 in that order during the first season (Table 11). In the second season, the top ten genotypes were Roslin Bvumbwe, Kenya Karibu, Ingabire, Kenya Sifa, Bishop Gitonga, Dutch Robyjn, Annet, Nyayo, Kihoro and clone 394034.7 in that order (Table 11). In the third season the top ten genotypes were Kenya Baraka, Kenya Karibu, Ingabire, Kenya Sifa, clone 394904.17, clone 394034.7, clone 393385.57, Roslin Bvumbwe, clone 394906.6 and lastly Kenya Mpya (Table 11). Potato genotype resistance to bacterial wilt as determined by ranking based on 
Table 13 Ranking for bacterial wilt resistance in the second season

\begin{tabular}{|c|c|c|c|c|c|c|c|}
\hline GENOTYPE & DTOW & PSTTW & PSTTN & FINAL BWI & $\%$ LI & Average Rank & Overall Rank \\
\hline Sherekea & 1.0 & 22.0 & 23.0 & 18.5 & 33.33 & 19.57 & 16.0 \\
\hline 394905.8 & 2.5 & 36.0 & 34.0 & 1.0 & 50.00 & 24.70 & 30.0 \\
\hline 387164.4 & 2.5 & 32.0 & 30.0 & 2.0 & 40.00 & 21.30 & 20.5 \\
\hline Roslin Tana & 7.5 & 10.5 & 15.0 & 26.0 & 46.67 & 21.13 & 19.0 \\
\hline Pimpernel & 7.5 & 34.0 & 33.0 & 8.5 & 40.00 & 24.6 & 29.0 \\
\hline Kerr's Pink & 7.5 & 23.0 & 25.5 & 34.0 & 40.00 & 26.00 & 33.0 \\
\hline Tigoni & 7.5 & 35.0 & 35.0 & 23.5 & 20.00 & 24.20 & 27.5 \\
\hline Bishop Gitonga & 7.5 & 26.0 & 20.0 & 30.5 & 6.67 & 18.13 & 11.0 \\
\hline Annete & 7.5 & 28.0 & 22.0 & 4.0 & 20.00 & 16.30 & 6.0 \\
\hline 394034.7 & 7.5 & 27.0 & 18.0 & 4.0 & 26.67 & 16.63 & 8.0 \\
\hline 393382.44 & 7.5 & 8.0 & 10.0 & 23.5 & 46.67 & 19.13 & 14.0 \\
\hline Sterling & 16.0 & 7.0 & 3.0 & 28.5 & 20.00 & 14.90 & 4.0 \\
\hline Purple Gold & 16.0 & 29.0 & 29.0 & 8.5 & 33.33 & 23.17 & 25.0 \\
\hline Nyayo & 16.0 & 18.0 & 16.0 & 18.5 & 33.33 & 20.37 & 17.0 \\
\hline Kihoro & 16.0 & 13.0 & 9.0 & 18.5 & 20.00 & 15.30 & 5.0 \\
\hline Kenya Sifa & 16.0 & 2.0 & 5.5 & 18.5 & 40.00 & 16.40 & 7.0 \\
\hline Kenya Mpya & 16.0 & 19.0 & 13.0 & 34.0 & 33.33 & 23.07 & 24.0 \\
\hline Kenya Mavuno & 16.0 & 21.0 & 27.0 & 8.5 & 20.00 & 18.50 & 13.0 \\
\hline Roslin Bvumbwe & 16.0 & 4.0 & 2.0 & 21.0 & 46.67 & 17.93 & 10.0 \\
\hline 394895.7 & 16.0 & 6.0 & 7.0 & 22.0 & 33.33 & 16.87 & 9.0 \\
\hline Kenya Karibu & 26.5 & 10.5 & 11.0 & 8.5 & 0.00 & 11.30 & 1.0 \\
\hline Romano & 26.5 & 15.0 & 19.0 & 14.0 & 33.33 & 21.57 & 22.0 \\
\hline Kenya Baraka & 26.5 & 30.0 & 25.5 & 14.0 & 60.00 & 31.20 & 35.0 \\
\hline Ingabire & 26.5 & 1.0 & 1.0 & 14.0 & 20.00 & 12.50 & 2.0 \\
\hline Dutch Robyjn & 26.5 & 5.0 & 8.0 & 32.0 & 0.00 & 14.30 & 3.0 \\
\hline Ddesiree & 26.5 & 12.0 & 12.0 & 26.0 & 30.00 & 21.30 & 20.5 \\
\hline Cangi & 26.5 & 31.0 & 24.0 & 30.5 & 13.33 & 25.07 & 31.0 \\
\hline B53 & 26.5 & 14.0 & 4.0 & 34.0 & 33.33 & 22.37 & 23.0 \\
\hline 396286.6 & 26.5 & 33.0 & 36.0 & 14.0 & 40.00 & 29.90 & 34.0 \\
\hline 394906.6 & 26.5 & 25.0 & 32.0 & 36.0 & 46.67 & 33.23 & 36.0 \\
\hline 394903.3 & 26.5 & 24.0 & 31.0 & 8.5 & 26.67 & 23.33 & 26.0 \\
\hline 393385.57 & 26.5 & 3.0 & 5.5 & 26.0 & 60.00 & 24.20 & 27.5 \\
\hline Meru & 34.0 & 16.0 & 17.0 & 28.5 & 6.67 & 20.43 & 18.0 \\
\hline Asante & 34.0 & 17.0 & 21.0 & 8.5 & 16.00 & 19.30 & 15.0 \\
\hline Arka & 34.0 & 9.0 & 14.0 & 14.0 & 20.00 & 18.20 & 12.0 \\
\hline 394904.17 & 36.0 & 20.0 & 28.0 & 4.0 & 40.00 & 25.60 & 32.0 \\
\hline
\end{tabular}

$\%$ LI, final BWI, DTOW, PSTTW and PSTTN showed that the five most resistant genotypes were Kenya Sifa, Kenya Baraka, Desiree, Kenya Mavuno and clone 394034.7 in the first season (Table 12). In the second season, the most resistant genotypes were Kenya Karibu, Ingabire, Dutch Robyjn, Sterling and Kihoro in that order (Table 13) while in the third season, the most resistant genotypes were Kenya Karibu, Kenya Baraka, Kenya Sifa, Ingabire and clone 394904.17 in that order (Table 14). When the most resistant genotypes across the seasons were ranked, Kenya Karibu was the most resistant followed by Kenya Sifa while Ingabire was third (Table 15).
Correlations Among Traits

Correlations between DTOW and final BWI were negative and non-significant in the first and second season (Table 16) and negative and significant in the third season (Table 17). Correlations between DTOW and PSTTW and between DTOW and PSTTN were negative and non-significant in the first season and, positive and non-significant in the second season (Table 16). The same applied to correlations between final BWI and PSTTW and between final BWI and PSTTN (Table 16). Correlation between DTOW and PSTTW was 
Table 14 Ranking for bacterial wilt resistance in the third season

\begin{tabular}{|c|c|c|c|c|c|c|c|}
\hline GENOTYPE & DTOW & PSTTW & PSTTN & FINAL BWI & $\% \mathrm{LI}$ & Average Rank & Overall Rank \\
\hline Ingabire & 2.5 & 5 & 3 & 9.0 & 3.0 & 4.5 & 4 \\
\hline Kenya Sifa & 5.0 & 3 & 4 & 2.0 & 4.0 & 3.6 & 3 \\
\hline Kenya Baraka & 2.5 & 2 & 2 & 4.0 & 2.0 & 2.5 & 2 \\
\hline 394906.6 & 13.5 & 8 & 11 & 35.0 & 18.5 & 17.2 & 14 \\
\hline 394034.7 & 9.0 & 9 & 12 & 19.0 & 8.5 & 11.5 & 7.5 \\
\hline 393382.44 & 9.0 & 10 & 13 & 7.0 & 24.5 & 12.7 & 9 \\
\hline Kenya Karibu & 1.0 & 1 & 1 & 3.0 & 1.0 & 1.4 & 1 \\
\hline 393385.57 & 20.0 & 4 & 7 & 6.0 & 20.5 & 11.5 & 7.5 \\
\hline Roslin Bvumbwe & 25.5 & 15 & 15 & 5.0 & 29.0 & 17.9 & 16 \\
\hline 394895.7 & 20.0 & 14 & 8 & 36.0 & 14.0 & 18.4 & 17 \\
\hline 394903.3 & 9.0 & 7 & 20 & 20.0 & 15.0 & 14.2 & 11 \\
\hline 396286.6 & 16.5 & 6 & 10 & 23.0 & 13.0 & 13.7 & 10 \\
\hline Sterling & 13.5 & 32 & 19 & 12.0 & 16.0 & 18.5 & 18 \\
\hline 394905.8 & 13.5 & 11 & 6 & 33.0 & 8.5 & 14.4 & 12 \\
\hline Annete & 30.0 & 13 & 29 & 15.5 & 24.5 & 22.4 & 25 \\
\hline Kenya Mavuno & 20.0 & 20 & 26 & 28.0 & 6.0 & 20 & 20 \\
\hline Nyayo & 25.5 & 24 & 32 & 15.5 & 31.0 & 25.6 & 29 \\
\hline 394904.17 & 9.0 & 12 & 5 & 1.0 & 8.5 & 7.1 & 5 \\
\hline Romano & 16.5 & 19 & 27 & 22.0 & 18.5 & 20.6 & 22 \\
\hline Asante & 25.5 & 35 & 16 & 14.0 & 11.5 & 20.4 & 21 \\
\hline Kenya Mpya & 20.0 & 23 & 21 & 17.0 & 17.0 & 19.6 & 19 \\
\hline Kerr's Pink & 30.0 & 17 & 23 & 24.0 & 33.0 & 25.4 & 28 \\
\hline Kihoro & 33.5 & 30 & 35 & 26.0 & 28.0 & 30.5 & 33 \\
\hline Sherekea & 13.5 & 26 & 14 & 34.0 & 20.5 & 21.6 & 23 \\
\hline Tigoni & 33.5 & 25 & 36 & 11.0 & 24.5 & 26 & 30 \\
\hline Arka & 9.0 & 18 & 24 & 13.0 & 8.5 & 14.5 & 13 \\
\hline Desiree & 20.0 & 21 & 17 & 18.0 & 11.5 & 17.5 & 15 \\
\hline B53 & 5.0 & 28.5 & 18 & 32.0 & 27.0 & 22.1 & 24 \\
\hline Meru & 25.5 & 16 & 28 & 21.0 & 36.0 & 25.3 & 27 \\
\hline 387164.4 & 5.0 & 22 & 9 & 10.0 & 5.0 & 10.2 & 6 \\
\hline Roslin Tana & 33.5 & 34 & 25 & 31.0 & 31.0 & 30.9 & 34 \\
\hline Cangi & 30.0 & 28.5 & 22 & 29.0 & 22.0 & 26.3 & 31 \\
\hline Pimpernel & 25.5 & 27 & 34 & 8.0 & 24.5 & 23.8 & 26 \\
\hline Purple Gold & 33.5 & 31 & 33 & 30.0 & 31.0 & 31.7 & 35 \\
\hline Bishop Gitonga & 25.5 & 33 & 31 & 27.0 & 35.0 & 30.3 & 32 \\
\hline Dutch Robyjn & 36.0 & 36 & 30 & 25.0 & 34.0 & 32.2 & 36 \\
\hline
\end{tabular}

negative and significant in the third season (Table 17). Correlation between \% LI and all the other traits were positive and non-significant in the first two seasons. In the third season, correlation between \% LI and DTOW was negative and significant while between \% LI and final BWI, was positive and significant (Table 17). From the evaluations eight potato genotypes were selected to be used as pollen donors (males) in subsequent crossing. These are Meru, Ingabire, Kenya Karibu, Sherekea, Kihoro, Tigoni, Bishop Gitonga and Cangi. The choice of these genotypes was also determined by pollen production (a good male needs to produce a lot of pollen), and popularity of the genotype with the Kenyan farmers.

\section{Discussion}

The high soil bacterial count at 60 days after planting was probably due to the fact that this coincided with periods of high rainfall. The aggressiveness of the pathogen is affected mainly by temperature and moisture; high temperature and high soil moisture promote survival, reproduction, infectivity, 
Table 15 Overall ranks of the most resistant potato genotypes across the three seasons at KARI Kabete

\begin{tabular}{|c|c|c|c|c|c|}
\hline \multirow[t]{2}{*}{ Genotype } & \multicolumn{3}{|c|}{ Ave. Ranks } & \multirow[b]{2}{*}{$\begin{array}{l}\text { Ave } \\
\text { rank }\end{array}$} & \multirow[b]{2}{*}{$\begin{array}{l}\text { Overall } \\
\text { Rank }\end{array}$} \\
\hline & $\begin{array}{l}\text { Season } \\
1\end{array}$ & $\begin{array}{l}\text { Season } \\
2\end{array}$ & $\begin{array}{l}\text { Season } \\
3\end{array}$ & & \\
\hline Kenya Sifa & 5.5 & 16.4 & 3.6 & 8.50 & 2 \\
\hline Kenya Baraka & 6.4 & 31.2 & 2.5 & 13.37 & 5 \\
\hline Desiree & 8.7 & 21.3 & 17.5 & 15.83 & 6 \\
\hline $\begin{array}{l}\text { Kenya } \\
\text { Mavuno }\end{array}$ & 11.5 & 18.5 & 20 & 16.67 & 7 \\
\hline 394034.7 & 11.6 & 16.63 & 11.5 & 13.24 & 4 \\
\hline Kenya Karibu & & 11.3 & 1.4 & 6.35 & 1 \\
\hline Ingabire & 17.5 & 12.5 & 4.5 & 11.50 & 3 \\
\hline Dutch & 22.8 & 14.3 & 32.2 & 23.10 & 11 \\
\hline sterling & 22 & 14.9 & 18.5 & 18.47 & 9 \\
\hline Kihoro & 21.1 & 15.3 & 30.5 & 22.30 & 10 \\
\hline 394904.17 & 20.4 & 25.6 & 7.1 & 17.70 & 8 \\
\hline
\end{tabular}

and spread of the bacterium, and hence disease development (Harris 1976; Martin and French 1985). This high soil bacterial population combined with the vigorous vegetative plant growth probably led to the rapid increase in the disease incidence (number of wilting plants) in the field (Figs. 1,2 and 3). At around flowering time, the plants' water demand is very high and they wilt rapidly due to the blockage of the xylem tissue by the bacterial mass. In addition, due to high transpiration rates, the plants take up a lot of water (together with bacteria in the soil water) and hence wilt rapidly. The higher soil bacterial population in the third season compared to the other two seasons could be due to accumulation of bacterial population in the soil over time (the same piece of land was used for three consecutive seasons), the high temperature and rainfall experienced in that period (Table 2) or a combination of all. Although the soil bacterial population was higher in the second season than in the first season, final BWI was higher in the first season. This is most likely due to lower temperatures experienced

Table 16 Pearson correlation coefficients for various agronomic traits for 36 genotypes during season I (top diagonal) and season II (bottom diagonal)

\begin{tabular}{lllllllcc}
\hline Trait & $\%$ LI & DTOW & FINAL BWI & PSTTN & PSTTW & PWTTW & TTN & TTW \\
\hline$\%$ LI & 1 & $0.037 \mathrm{~ns}$ & $0.062 \mathrm{~ns}$ & $0.048 \mathrm{~ns}$ & $0.063 \mathrm{~ns}$ & $-0.082 \mathrm{~ns}$ & $0.181 \mathrm{~ns}$ & $0.071 \mathrm{~ns}$ \\
DTOW & $0.210 \mathrm{~ns}$ & 1 & $-0.146 \mathrm{~ns}$ & $-0.121 \mathrm{~ns}$ & $-0.153 \mathrm{~ns}$ & $0.052 \mathrm{~ns}$ & $0.015 \mathrm{~ns}$ & $-0.220^{*}$ \\
FINAL BWI & $-0.108 \mathrm{~ns}$ & $-0.025 \mathrm{~ns}$ & 1 & $-0.086 \mathrm{~ns}$ & $-0.180 \mathrm{~ns}$ & $0.083 \mathrm{~ns}$ & $0.170 \mathrm{~ns}$ & $0.157 \mathrm{~ns}$ \\
PSTTN & $0.175 \mathrm{~ns}$ & $0.129 \mathrm{~ns}$ & $0.135 \mathrm{~ns}$ & 1 & $0.424^{*}$ & $0.004 \mathrm{~ns}$ & $-0.393^{*}$ & $-0.296^{*}$ \\
PSTTW & $0.095 \mathrm{~ns}$ & $0.187 \mathrm{~ns}$ & $0.100 \mathrm{~ns}$ & $0.939^{*}$ & 1 & $-0.175 \mathrm{~ns}$ & $-0.357^{*}$ & $-0.128 \mathrm{~ns}$ \\
PWTTW & $0.071 \mathrm{~ns}$ & $-0.080 \mathrm{~ns}$ & $-0.015 \mathrm{~ns}$ & $-0.767 *$ & $-0.833^{*}$ & 1 & $0.066 \mathrm{~ns}$ & $0.234^{*}$ \\
TTN & $0.041 \mathrm{~ns}$ & $0.030 \mathrm{~ns}$ & $-0.006 \mathrm{~ns}$ & $-0.032 \mathrm{~ns}$ & $0.006 \mathrm{~ns}$ & $0.074 \mathrm{~ns}$ & 1 \\
TTW & $0.029 \mathrm{~ns}$ & $-0.041 \mathrm{~ns}$ & $0.137 \mathrm{~ns}$ & $-0.359^{*}$ & $-0.372^{*}$ & $0.524^{*}$ & $0.708^{*}$ & 1 \\
\hline
\end{tabular}

$\% L I \%$ latent infection, DTOW days to onset of wilting, FINAL BWI bacterial wilt incidence at 120 days after planting, TTN total tuber number per hectare, PSTTN percent of symptomatic tubers ( $\%$ of total tuber number per hectare), TTW total tuber weight (ton ha ${ }^{-1}$ ), PSTTW percent of symptomatic tubers $\left(\%\right.$ of total tuber weight in ton $\left.\mathrm{ha}^{-1}\right), P W T T W$ percent of ware sized tubers $\left(\%\right.$ of total tuber weight in ton ha ${ }^{-1}$ )

$*=$ significant at $P \leq 0.05$

Table 17 Pearson correlation coefficients for various agronomic traits for 36 genotypes during the third season

\begin{tabular}{|c|c|c|c|c|c|c|c|c|}
\hline Trait & $\% \mathrm{LI}$ & DTOW & FINAL BWI & PSTTN & PSTTW & PWTTW & TTN & TTW \\
\hline$\%$ LI & 1 & & & & & & & \\
\hline DTOW & $-0.654 *$ & 1 & & & & & & \\
\hline FINAL BWI & $0.455^{*}$ & $-0.433^{*}$ & 1 & & & & & \\
\hline PSTTN & $0.524 *$ & $-0.609 *$ & $0.531 *$ & 1 & & & & \\
\hline PSTTW & $0.473 *$ & $-0.478^{*}$ & $0.241 \mathrm{~ns}$ & $0.291 \mathrm{~ns}$ & 1 & & & \\
\hline PWTTW & $-0.428^{*}$ & $0.325 \mathrm{~ns}$ & $-0.169 \mathrm{~ns}$ & $-0.223 \mathrm{~ns}$ & $-0.387^{*}$ & 1 & & \\
\hline TTN & $-0.009 \mathrm{~ns}$ & $0.108 \mathrm{~ns}$ & $-0.122 \mathrm{~ns}$ & $-0.370^{*}$ & $0.222 \mathrm{~ns}$ & $0.196 \mathrm{~ns}$ & 1 & \\
\hline TTW & $-0.184 \mathrm{~ns}$ & $0.221 \mathrm{~ns}$ & $-0.270 \mathrm{~ns}$ & $-0.477 *$ & $-0.016 \mathrm{~ns}$ & $0.571 *$ & $0.713 *$ & 1 \\
\hline
\end{tabular}

$\%$ LI \% latent infection, DTOW days to onset of wilting, FINAL BWI bacterial wilt incidence at 120 days after planting, TTN total tuber number per hectare, PSTTN percent of symptomatic tubers ( $\%$ of total tuber number per hectare), $T$ TW total tuber weight (ton ha ${ }^{-1}$ ), PSTTW percent of symptomatic tubers ( $\%$ of total tuber weight in ton $\left.\mathrm{ha}^{-1}\right), P W T T W$ percent of ware sized tubers $\left(\%\right.$ of total tuber weight in ton ha $\left.{ }^{-1}\right)$

*=significant at $P \leq 0.05$ 
during the second season compared to the first season (Table 2). Disease expression in the field is favoured by high temperatures (Hayward 1991; French 1994; EPPO 2004). The high total tuber weight (TTW) in the second season was likely due to the heavy rainfall and lower temperatures experienced in that season. The heavy rains and cool conditions favoured crop growth because potato is a cool season crop. These conditions also led to the high PWTTW and TTN.

In terms of resistance, the genotypes ranked differently in all the seasons (Table 12, 13 and 14). This could be due to differences in weather among the seasons especially with regards to temperature and rainfall. Resistance to $R$. solanacearum available in Solanum tuberosum originated mainly from the cultivated diploid, Solanum phureja (Martin and French 1985). This resistance is very unstable due to strong host-pathogen-environment interaction; hosts resistant to the disease in 1 year/environment or location may succumb to the disease in the other year/ environment or location (French and Lindo 1982; Tung et al. 1990, 1992b, 2006; Tung 1992). Previously, varieties Kenya Dhamana (CIP-800228), Kenya Sifa, Kenya Karibu, Mauritius clone (89016), and Cruza-148 (CIP-720118) were rated as resistant to bacterial wilt, while varieties Asante (CIP-381381.20), Tigoni (CIP-381381.13), Nyayo, and Dutch Robyjin were highly susceptible (Ateka et al. 2001). In a later study it was found that Kenya Sifa and Kenya Karibu were the most resistant to bacterial wilt while Dutch Robjyn and Tigoni were the most susceptible (Felix et al. 2010). The present study found Kenya Karibu to be the most resistant followed by Kenya Sifa while Ingabire was third. The negative correlation between final BWI and DTOW means that genotypes that took long before onset of wilting had a lower final BWI. Correlation between latent infection and all the other traits was not consistent. According to some reports, $R$. solanacearum expresses different sets of genes during latent infection and during symptomatic disease development (Jill et al., 2004).

Acknowledgments Due thanks go to the Alliance for a Green Revolution in Africa (AGRA) for funding this research and Kenya Agricultural Research Institute (KARI) for granting study leave to the first author. The entire members of staff at KARI Kabete plant pathology section are highly acknowledged.

Open Access This article is distributed under the terms of the Creative Commons Attribution License which permits any use, distribution, and reproduction in any medium, provided the original author(s) and the source are credited.

\section{References}

Alacho, F.O., and D.R. Akimanzi. 1993. Progress, achievements, and constraints on bacterial wilt control in Uganda. In Workshop on Bacterial Wilt of Potato caused by Pseudomonas solanacearum, Bujumbura, Burundi, 32-41. Kampala: African Potato Association.
Ateka, E.M., A.W. Mwang'ombe, and J.W. Kimenju. 2001. Reaction of potato cultivars to Ralstonia solanacearum in Kenya. African Crop Science Journal 9: 251-256.

Champoiseau, P.G., J.B. Jones, and C. Allen. 2009. Ralstonia solanacearum race 3 biovar 2 causes tropical losses and temperate anxieties [Online]. Madison: American Phytopathological Society. Available at http://www.apsnet.org/online/feature/ralstonia/ (Accessed 25 June 2010).

Champoiseau, P.G., J.B. Jones, T.M. Momol, J. Pingsheng, C. Allen, D.J. Norman, C. Harmon, S.A. Miller, T. Schubert, D. Bell, J.P. Floyd, D. Kaplan, R. Bulluck, K. Smith, and K. Caldwell. 2010. Ralstonia solanacearum Race 3 biovar 2 causing brown rot of potato, bacterial wilt of tomato and southern wilt of geranium [Online]. Madison: American Phytopathological Society. Available at http:// plantpath.ifas.ufl.edu/rsol/NRI_Project/Projectsummary.html (Accessed 25 June 2010).

Englebrecht, M.C. 1994. Modification of a selective medium for the isolation and quantification of Pseudomonas solanacearum. Australian Centre for International Agricultural Research Bacterial Wilt Newsletter 10: 3-5.

EPPO. 2004. Ralstonia solanacearum. European and Mediterranean Plant Protection Organization Bulletin 34: 173-178.

Felix, R., O.J. Onyango, and O.M. Eliazer. 2010. Assessment of irish potato cultivars' field tolerance to bacterial wilt (Ralstonia solanacearum) in Kenya. Plant pathology Journal (Faisalabad) 9: 122-128.

French, E.R. 1994. Strategies for integrated control of bacterial wilt of potatoes. In Bacterial wilt: The disease and its causative agent, Pseudomonas solanacearum, ed. A.C. Hayward and G.L. Hartman, 98-113. UK: CAB International.

French, E.R., and L.D. Lindo. 1982. Resistance to Pseudomonas solanacearum in potato: Specificity and temperature sensitivity. Phytopathology 72: 1408-1412.

Grimsley, N., and P. Hanson. 1998. Genetics of plant resistance to bacterial wilt: Round table report. In Bacterial wilt disease: Molecular and ecological aspects. Report of the Second International Wilt Symposium, Gosier, Guadeloupe, France. 22-27 June 1997, ed. P. Prior et al., 263-266. Berlin: Springer.

Harris, O.C. 1976. Bacterial wilt in Kenya with particular reference to potatoes. In Proceedings of the first international planning conference and workshop on the ecology and control of bacterial wilt caused by Pseudomonas solanacearum, Raleigh, North Carolina.18-24 January 1976, ed. L. Sequeira and A. Kelman, 84-88. Berlin: Springer.

Hayward, A.C. 1991. Biology and epidemiology of bacterial wilt caused by Pseudomonas solanacearum. Annual Review of Phytopathology 29: 65-87.

Jaetzold, R., H. Schmidt, B. Hornetz, and C. Shisanya. 2006. Farm Management Handbook of Kenya. Natural conditions and farm management information. Part B. Central Kenya. Subpart B2. South Rift. Vol. II, 2nd ed. Nairobi: Ministry of Agriculture.

Jill, K.S., Y. Jian, T.K. Julie, and C. Allen. 2004. Behaviour of R. solanacearum race 3 biovar 2 during latent and active infectionof geranium. Phytopathology 95:136-143.

Kabira, J. N., M. Wakahiu, W. Wagoire, P. Gildemacher and B. Lemaga. 2006. Guidelines for production of healthy seed potatoes in East and Central Africa.

Kaguongo, W.P., P. Gildemacher, P. Demo, W. Wagoire, P. Kinyae, J. Andrade, G. Forbes, K. Fuglie, and G. Thiele. 2008. Farmer practices and adoption of improved potato varieties in Kenya and Uganda. Social Sciences Working Paper 2008-5. Lima: Centro Internacional de la Papa.

Kakuhenzire, B., F. Alacho, J. Birikunzira, G. Turyamureeba, and L. Dikka. 1993. Progress in field evaluation for resistance to Pseudomonas and cultural methods for control of bacterial wilt in Uganda. In Proceedings of Workshop on Bacterial Wilt of Potato caused by Pseudomonas solanacearum, Bujumbura, Burundi. 22 26 February 1993, 76-82. Kampala: African Potato Association. 
Martin, C., and E.R. French. 1985. Bacterial wilt of potatoes caused by Pseudomonas solanacearum. Technical Information Bulletin 13: 1-6. Centro Internacional de la Papa, Lima, Peru.

Muthoni, J., M.W. Mbiyu, and D.O. Nyamongo. 2010. A review of potato seed systems and germplasm conservation in Kenya. Journal of Agricultural and Food Information 11: 157-167.

Otipa, M.J., M.W. Wakahiu, P.M. Kinyae, D.M. Thuo, and J.I. Kinoti. 2003. Survey of the bacterial wilt of potatoes caused by Ralstonia solanacearum and its spread in major potato growing areas of Kenya. Task Force Report. Nairobi: KARI.

Payne, R.W., D.A. Murray, S.A. Harding, D.B. Baird, and D.M. Soutar. 2011. GenStat for Windows (14th Edition) Introduction. Hemel Hempstead: VSN International.

Priou, S., L. Gutarra, and P. Aley. 1999. Highly sensitive detection of Ralstonia solanacearum in latently infected potato tubers by postenrichment ELISA on nitrocellulose membrane. EPPO/OEPP Bulletin 29: 117-125.

Smith, J.J., L.C. Offord, M. Holderness, and G.S. Saddler. 1998. The development of biological control against race 3 in Kenya. In Bacterial wilt disease: Molecular and ecological aspects. Report of the Second International Wilt Symposium, Gosier, Guadeloupe, France. 22-27 June 1997, ed. P. Prior et al., 337-342. Berlin: Springer.

SPSS Inc. 2009. Statistical Package for Social Scientists. SPSS for Windows Release 18.0. 2009. Chicago: SPSS Inc. 2009. www.spss.com.
Steel, R.G.D., and J.H. Torrie. 1980. Principles and procedures of statistics: A biometrical approach, 2nd ed. New York: McGraw-Hill.

Tung, P.X. 1992. Genetic variation for bacterial wilt resistance in a population of tetraploid potato. Euphytica 61: 73-80.

Tung, P.X., E.T. Rasco, P.V. Zaag, and P. Schmiediche. 1990. Resistance to Pseudomonas solanacearum in the potato: I. Effects of sources of resistance and adaptation. Euphytica 45: 203-210.

Tung, P.X., J.G.T. Hermsen, P.V. Zaag, and P. Schmiediche. 1992a. Effects of resistance genes, heat tolerance genes and cytoplasms on expression of resistance to Pseudomonas solanacearum (E.F. Smith) in potato. Euphytica 60: 127-138.

Tung, P.X., J.G.T. Hermsen, P.v.d. Zaag, and P. Schmiediche. 1992b. Effects of heat tolerance on expression of resistance to Pseudomonas solanacearum E. F. Smith in potato. Potato Research 35: 321-328.

Tung, P.X., J.G. Hermsen, P.Z. Vander, and P.E. Schmiediche. 2006. Inheritance of resistance to Pseudomonas solanacearum in tetraploid potato. Plant Breeding 111: 23-30.

UNESCO. 1977. FAO-UNESCO Soil Map of the World. Vol. VI. Africa . Paris: UNESCO.

Yabuuchi, E., Y. Kosako, I. Yano, H. Hotta, and Y. Nishiuchi. 1995. Transfer of two Burkholderia and an Alcaligenes species to Ralstonia genus nov.: proposal of Ralstonia pickettii (Ralston, Palleroni and Douderoff 1973) comb.nov., Ralstonia solanacearum (Smith 1896) comb. nov. and Ralstonia eutropha (Davis 1969) comb. nov. Microbiology and Immunology 39: 897-904. 